\title{
The efficiency of an open-cavity tubular solar receiver for a small-scale solar thermal Brayton
}

\section{cycle}

\author{
W.G. Le Roux ${ }^{\mathrm{a}}$ \\ T. Bello-Ochende*b \\ J.P. Meyer \\ ${ }^{a}$ Department of Mechanical and Aeronautical Engineering, University of Pretoria, \\ Private Bag X20, Hatfield, Pretoria, 0028, South Africa \\ ${ }^{\mathrm{b}}$ Department of Mechanical Engineering, University of Cape Town, \\ Private Bag X3, Rondebosch, 7701, South Africa \\ E-mail address: willemleroux@gmail.com, tunde.bello-ochende@uct.ac.za, josua.meyer@up.ac.za \\ *Corresponding author: Tel: +27 21650 3673; fax: +27 216503240 \\ E-mail address: tunde.bello-ochende@uct.ac.za
}

\begin{abstract}
The first law and second law efficiencies are determined for a stainless steel closed-tube open rectangular cavity solar receiver. It is to be used in a small-scale solar thermal Brayton cycle using a micro-turbine with low compressor pressure ratios. There are many different variables at play to model the air temperature increase of the air running through such a receiver. These variables include concentrator shape, concentrator diameter, concentrator rim angle, concentrator reflectivity, concentrator optical error, solar tracking error, receiver aperture area, receiver material, effect of wind, receiver tube diameter, inlet temperature and mass flow rate through the receiver. All these variables are considered in this paper. The Brayton cycle requires very high receiver surface temperatures in order to be successful. These high temperatures, however, have many disadvantages in terms of heat loss from the receiver, especially radiation heat loss. With the help of ray-tracing software, SolTrace, and receiver modelling techniques, an optimum receiver-to-concentrator-area ratio of $A^{\prime} \approx 0.0035$ was found for a concentrator with $45^{\circ}$ rim angle, 10 mrad optical error and $1^{\circ}$ tracking error. A method to determine the temperature profile and net heat transfer rate along the length of the receiver tube is presented. Receiver efficiencies are shown in terms of mass flow rate, receiver tube diameter, pressure drop, maximum receiver surface temperature and inlet temperature of the working fluid. For a $4.8 \mathrm{~m}$ diameter parabolic dish, the larger the receiver tube diameter and the smaller the mass flow rate through the receiver, the higher the receiver surface temperature and the less efficient the collector becomes. However, the smaller the receiver tube diameter, the higher the pressure drop through the tube and the smaller the second law efficiency. It was found that the
\end{abstract}


receiver with larger tube diameter would perform better in a solar thermal Brayton cycle. An overall solar-to-heat efficiency of between $45 \%$ and $70 \%$ is attainable for the solar collector using the open-cavity receiver.

Keywords: solar, receiver, cavity, tracking, Brayton, efficiency

\section{Introduction and background}

\subsection{The solar thermal Brayton cycle}

The closed Brayton cycle was developed in the 1930s for power applications [1]. The technology was adapted to the design and development of solar thermal Brayton cycles for space power in the 1960s, with the success of lightweight and high-performance gas turbines for aircraft. Testing of the solar thermal Brayton cycle proved high reliability and efficiencies above $30 \%$ with turbine inlet temperatures of between $1033 \mathrm{~K}$ and $1144 \mathrm{~K}$ [1].

This paper investigates an open-cavity receiver used in a small-scale solar thermal Brayton cycle with micro-turbine. The open Brayton cycle uses air as working fluid, which makes this cycle very attractive for use in water-scarce countries. The open and direct solar thermal Brayton cycle is shown in Fig. 1 [2]. The parabolic dish concentrator is used to reflect and concentrate the sun's rays onto the receiver aperture so that the solar heat can be absorbed by the inner walls of the receiver. The heat is then transferred to the working fluid (air). The compressor increases the air pressure before the air is heated in the receiver. The compressed and heated air expands in the turbine, which produces rotational power for the compressor and the electric load.

In the recuperator, hot exhaust air preheats the colder air before it enters the receiver. For the solar thermal Brayton cycle, high recuperator effectiveness is mostly chosen to maximise efficiency [1]. The recuperator in the cycle assists the receiver in heating the air from ambient temperature. The recuperator also allows for lower operating pressures in the receiver. The receiver in this paper is a low-pressure receiver as it is to be operated with low-pressure turbomachinery operating between 1.3 and 2.5 times the ambient pressure [2-5]. According to [6], solarised Brayton microturbines are adapted from the small stationary gas turbine market, which allows for lower costs due to high production quantities in the stationary market.

The importance of optimising the components of the solar thermal Brayton cycle for a common goal is emphasised. A solar receiver might be designed for high efficiency; however, when coupled to a Brayton cycle, it might not perform well, due to it not being optimised to achieve a common goal together with the other components. A variety of parametric studies were done on different variations of the Brayton cycle and the solar thermal Brayton cycle. A parametric study on the closed recuperative Brayton cycle was done [7]. A closed recuperative Brayton cycle with 
intercooling [8] and with both intercooling and reheat [9] was also modelled and parametric studies were done. The efficiency and power output of these cycles were optimised. A closed recuperative solar thermal Brayton cycle with helium as working fluid was also studied [10]. The small-scale solar thermal Brayton cycle with recuperator has been thermodynamically optimised in recent work [2-5].

\subsection{Solar cavity receiver}

Solar receivers can be divided into tubular, volumetric and particle receivers. A chronological review of the volumetric solar receivers of most interest for electricity production in the $10 \mathrm{MW}-200 \mathrm{MW}$ range was published [11]. A summary of the latest volumetric, particle and tubular receivers studied for central receiver (tower) plants is also available [12]. A particle receiver is demonstrated by [13]. The tubular receiver studied in this paper, however, is for output in the small-scale range of $1 \mathrm{~kW}-100 \mathrm{~kW}$.

\subsubsection{Temperature and efficiency}

A solar cavity receiver is used to capture the solar radiation coming from the dish concentrator (Fig. 1). Equation (1) shows how the overall efficiency of the solar thermal Brayton cycle is calculated.

$\eta_{S T B C}=\eta_{c o l} \eta_{B C}=\eta_{\text {refl }} \eta_{R E C} \eta_{B C}$

where

$\eta_{R E C}=\eta_{\text {rec }} \eta_{\text {optical }}$

For the open and direct solar thermal Brayton cycle, the maximum receiver surface temperature is very important. The higher this temperature, the better the Brayton cycle will perform [4], but also the more heat will be lost to the environment. In addition, the higher this temperature, the less receiver material choices are available. Most Brayton cycles are not self-sustaining at operating temperatures below $480{ }^{\circ} \mathrm{C}$ [14]. For open-cavity receivers, overall collector efficiencies of between $60 \%$ and $70 \%$ are attainable with state-of-the-art systems operated in the temperature range of $500{ }^{\circ} \mathrm{C}-900{ }^{\circ} \mathrm{C}$ with an optimum area ratio of $0.0004 \leq A^{\prime} \leq 0.0009[15]$.

A number of high-temperature and high-efficiency receivers are available from the literature. These receivers are mostly not optimised to perform well in a small-scale solar thermal Brayton cycle. Typical receiver efficiencies and 
experimental data that have been obtained with pressurised volumetric receivers and tubular receivers are shown in Table 1. These receivers operate at higher pressures than which are studied in this paper. The receiver efficiency found in this work can be compared with the efficiencies of the state-of-the art receivers shown in Table 1. The receiver efficiency is defined as

$$
\eta_{\text {rec }}=\dot{Q}_{n e t} / \dot{Q}^{*}=\dot{m} c_{p 0}\left(T_{\text {out }}-T_{\text {in }}\right) / \eta_{\text {optical }} \eta_{\text {refl }} \dot{Q}_{\text {solar }}
$$

A tubular open-cavity solar receiver as a heat source for an $11 \mathrm{kWe}$ recuperative Brayton cycle using $\mathrm{Cb}$-1Zr-alloy together with Li-F heat storage with $1120 \mathrm{~K}$ as melting temperature was successfully tested in 1972 [16]. A mixture of helium and xenon was used as working fluid. Such a receiver with heat storage was also modelled by [17]. In this receiver, the flow is divided into tubes flowing across the length of the receiver cavity. It was found by [18] and [19] that the receiver output power (and therefore efficiency) increases for a tubular receiver, as the flow rate increases, while the air exit temperature decreases. Inconel 600 was used for a tubular solar receiver by [18], supplying about $700{ }^{\circ} \mathrm{C}$ as a pre-heater for a secondary solar receiver.

The design of tubular air receivers is challenging due to the combined effects of thermal oxidation, material creep, pressur-induced stress, daily thermal cycling, and thermal shocks [20]. A lifetime study was done [20] for a 4 MW solar receiver made of Inconel 617 operating at $900 \mathrm{kPa}$. A turbine inlet temperature of $1120 \mathrm{~K}$ is a necessary upper limit for tube reliability [20]. The bent tube in a receiver coil is very flexible and thus reduces mechanical stresses from thermal expansion of the tube material [21]. A small-scale Brayton tubular silicon carbide receiver with an aperture diameter of $72 \mathrm{~mm}$ and a $17 \mathrm{~m}^{2}$ dish area was proposed by [22]. The receiver is designed to heat air up to $1500 \mathrm{~K}$.

\subsubsection{Shape and design}

For the same receiver cavity aperture and insulation thickness, cavity geometry has almost no effect on system efficiency $[15,23]$. The primary effects of cavity geometry and concentrator rim angle are to vary the flux distribution on the inner-receiver walls. According to [23], manufacturing and assembly errors and unideal sunlight create a bigger solar spot in the focal region of a dish and a non-uniformity of heat flux distribution or local overheating in the cavity receiver. An upside-down pear-shaped cavity receiver would be the best to prevent local overheating in the cavity receiver [23]. The study included the effects of slope error and sun-shape but excluded the effects of tracking and specularity error.

For a volumetric solar receiver coupled with the Brayton cycle, a pressurised volumetric receiver is required and thus a window cover must be used. According to [11], many studies have demonstrated that the window poses a difficult 
design problem. The problems are related to optical properties, mechanical strength, sealing and cooling capabilities, variable working temperatures and stress-free installation. A novel pressurised volumetric air cavity receiver without a glass window was presented by [19]. The receiver has an outlet temperature of $1000{ }^{\circ} \mathrm{C}$ at 10 bar, with predicted thermal efficiency of $78 \%$.

According to [15], the use of a closed-cavity receiver with an aperture window may be questionable since radiation and convection heat losses could be in the neighbourhood of $12 \%$ of the energy entering the cavity, while a fused quartz or other high-temperature window will have an overall transmittance in the neighbourhood of $90 \%$. In addition, there will still be radiant and conduction losses associated with the aperture window. The use of a window may thus only introduce an additional system cost. It should be noted that the optimum receiver aperture sizes found by [15] were very small, since more accurate optics and tracking were considered. In an open Brayton cycle using air as working fluid and with less accurate optics, however, a larger receiver is required and therefore the radiation and convection heat losses can be much higher. The use of a window might be beneficial, especially as the receiver aperture size increases. The use of a glass window with a specific coating often works well at lower temperatures. However, at the high temperatures being investigated in this paper, these coatings are often not available. The study of a receiver with a quartz glass cover is available from [24]. In their work, a maximum temperature of $1073 \mathrm{~K}$ was investigated.

\subsection{Summary of the objectives}

The receiver presented in this work is a rectangular open-cavity receiver constructed with a stainless steel tube through which air flows (See Fig. 2). Air enters the tube at the bottom of the receiver and heated air exits at the top. The receiver tube forms the inner wall of the open-cavity receiver. For this specific open-cavity receiver design coupled with a solar thermal Brayton cycle, an optimum mass flow rate and receiver tube diameter must exist for the system to deliver maximum net power output. The benefit of the receiver investigated in this paper is that it will be a simple, low-cost receiver, since it operates at low pressure [2-5]. The authors wish to optimise this specific design of receiver. The authors are well aware of other receiver designs available from the literature, for example, [11-13, 16, 18, 19, 21-30] and receivers referred to by [5]. However, these receivers often come with added costs and complexity. The size of the receiver aperture can be optimised by considering factors such as heat loss and errors due to the solar dish and tracking system. The aim of the paper is to propose a method for determining the receiver surface temperatures and receiver efficiencies for various sizes of cavities with different tube diameters. With this method, the entropy generation rate due to such a receiver can be obtained and used to determine the net power output of a solar thermal Brayton cycle [5]. 


\section{Modelling and governing equations}

The factors contributing to the temperature profile and net heat transfer rate on the receiver wall can be divided into two components: geometry-dependent and temperature-dependent.

The geometry-dependent factors include the concentrator dish with its optics: tracking error, reflectance, spillage and shadowing. The effects of these factors can be found with SolTrace. For a specific ratio of receiver aperture area vs. concentrator area, $A^{\prime}$, the solar heat flux available at the different wall positions in the open-cavity receiver can be determined, irrespective of receiver temperature.

The temperature-dependent factors include radiation heat loss to the environment, reradiation from the inner-cavity walls, convection heat loss and conduction heat loss. These factors depend on the surface temperatures at the different parts of the receiver.

\subsection{Solar dish and tracking system}

\subsubsection{Solar tracking error}

A two-axis tracking system is modelled for the dish-mounted solar receiver to ensure that the sun's rays stay focused on the receiver aperture throughout a typical day. From the literature, typical solar tracking errors of $0.1^{\circ}-0.3^{\circ}[31], 0.2^{\circ}$ [32], $0.4^{\circ}[33], 0.6^{\circ}-0.7^{\circ}\left[34\right.$ ], less than $1^{\circ}[35], 1^{\circ}[36]$ and $\pm 1^{\circ}-2^{\circ}$ commercially [37] were identified. Error due to wind loading is also a measurable quantity [37]. The accuracy of the tracking system is often an important factor for the total cost of a system. A two-axis solar tracking error range of $0^{\circ}$ to $2^{\circ}$ is considered in this work.

\subsubsection{Reflectance, slope error and specularity error}

A concentrator dish has to reflect the sun's rays onto the receiver. The rim angle of the parabolic dish determines where its focal point is. Dish manufacturing and installation errors can change the position of the focal point. For a solar concentrator, good reflectance and specular reflection of the entire terrestrial solar spectrum are important [14, 38, 39]. According to [14], a typical total effective error is $6.7 \mathrm{mrad}$. According to [40], a typical slope error for a stretched membrane dish is around $3 \mathrm{mrad}$. Typical slope errors are 1.75, 3 and $5 \mathrm{mrad}$, while specularity errors range between 0 and $3.84 \mathrm{mrad}$ [41]. According to [42], $3 \mathrm{mrad}$ is a typically acceptable value for a specularity error of a parabolic trough mirror material. In this work, the effect of reflectivity and optical errors on the intercepted heat rate and surface temperature of an open-cavity receiver is investigated. 


\subsubsection{SolTrace modelling}

SolTrace is a software tool developed at the National Renewable Energy Laboratory (NREL) to model concentrating solar power optical systems and analyse their performance. SolTrace is recommended by [43] as a free and readily available plant performance code for solar receiver research. Figure 3 shows an example of the use of SolTrace for this study. A parabolic dish rim angle of $45^{\circ}$ is investigated. In SolTrace, optical errors in the range of 0 to $50 \mathrm{mrad}$ and tracking errors in the range of $0^{\circ}$ to $2^{\circ}$ are investigated to determine the effect on the performance of the open-cavity receiver. According to SolTrace, the optical error of the dish is determined from the slope error and specularity error as shown in Eq. (4).

$\omega_{\text {optical }}=\left(4 \omega_{\text {slope }}^{2}+\omega_{\text {specularit }}^{2}\right)^{1 / 2}$

A pillbox sun-shape is assumed in the analysis since a Gaussian sun-shape is not recommended for highly accurate systems. The parameter for the pillbox, being a flat distribution, is simply the half-angle width, chosen as 4.65 mrad. SolTrace also includes the effect of the shade of the receiver on the concentrator. SolTrace is used to get the solar power available at different sizes of receiver apertures. It is also used to get the solar heat flux available at the inner walls of the receiver. The reflectance of the cavity walls is assumed to be $15 \%$ (oxidised stainless steel), and SolTrace accounts for this reflectance to determine the final solar heat flux available. The radiation heat flux from the inner walls of the receiver onto the other inner walls is temperature-dependent and cannot be modelled by SolTrace.

\subsection{Receiver modelling}

The receiver model is shown in Fig. 4. The receiver (Fig. 2) is covered with insulation. The heat loss from the receiver consists of convection, radiation and conduction heat loss. For the rectangular cavity receiver studied in this paper, the depth of the receiver is equal to $2 a$.

The net heat transfer rate at the receiver tube is

$\dot{Q}_{n e t}=\dot{Q}^{*}-\dot{Q}_{l o s s, \text { rad }}-\dot{Q}_{\text {loss,cond }}-\dot{Q}_{\text {loss,conv }}$

The different methods of modelling heat loss from an open-cavity receiver are available from $[15,44-52]$ in the form of conduction, convection and radiation heat loss. 


\subsubsection{Conduction heat loss}

For the receiver insulation, a high-temperature ceramic fibre insulation can be used. The conduction heat loss rate can be calculated with Eq. (6) by assuming an average wind speed of $2.5 \mathrm{~m} / \mathrm{s}$ for Pretoria. Note that an average surrounding temperature of $300 \mathrm{~K}$ and atmospheric pressure of $86.6 \mathrm{kPa}$ is assumed throughout the paper.

$$
\dot{Q}_{\text {loss }, \text { cond }}=A\left(T_{s, \text { ave }}-T_{\infty}\right) / R_{\text {total }}=\left(T_{s, \text { ave }}-T_{\infty}\right) /\left(1 / h_{\text {outer }} A+t_{\text {ins }} / k_{\text {ins }} A\right)
$$

An insulation thickness of $t_{\text {ins }}=0.1 \mathrm{~m}$ is assumed for the receiver walls. An average insulation conductivity of $0.061 \mathrm{~W} / \mathrm{mK}$ at $550{ }^{\circ} \mathrm{C}$ is assumed [15]. The convection heat transfer coefficient on the outside of the insulation is determined by assuming a combination of natural convection and forced convection due to wind. It is assumed that the receiver will be operating at an average angle of $45^{\circ}$ for most of its lifetime in Pretoria and that the wind will mostly be either from the side or the back, since the dish would be shielding the receiver from wind. It is assumed that the effect of wind on the insulation is compared with forced convection on a flat plate for two sides of the receiver and for the receiver top, and compared with a rectangular shape in forced convection for the other two sides of the receiver. The Nusselt number for forced convection for the combined laminar and turbulent flow over the receiver insulation on the sides in parallel with the wind direction is [53]:

$$
N u=h_{\text {sidel }} L / k=\left(0.037 \operatorname{Re}_{L}^{0.8}-871\right) \operatorname{Pr}^{1 / 3}
$$

The Nusselt number for forced convection on the other sides of the receiver is [54]:

$$
N u=h_{\text {side } 2} L / k=0.102 \operatorname{Re}^{0.675} \operatorname{Pr}^{1 / 3}
$$

The Nusselt number for natural convection on the vertical sides of the receiver is [55]:

$$
N u=0.59 R a_{L}{ }^{1 / 4}
$$

It is assumed that the Nusselt number for natural convection on the upper tilted side of the receiver is the same as the lower tilted side [53]: 
$N u=0.59 R a_{L}{ }^{1 / 4}(\cos \theta)^{1 / 4}$

where $\theta$ is $45^{\circ}$.

For the combined natural and forced convection, the Nusselt number is $[53,56]$ :

$$
N u_{\text {combined }}=\left(N u_{\text {forced }}^{3.5}+N u_{\text {natural }}^{3.5}\right)^{1 / 3.5}
$$

From these equations, in the range of receiver apertures of up to $2 \mathrm{~m}$ diameter, assuming an average heat transfer coefficient over the whole receiver, it was found that

$\left(1 / h_{\text {outer }}+t_{\text {ins }} / k_{\text {ins }}\right) \approx 1.86$

The emissivity of the ceramic fibre insulation is assumed to be 0.9 at normal temperatures [57]. For the purpose of this paper, the heat loss from the receiver insulation due to radiation is neglected as the surface temperature of the insulation is assumed to be close to the environment temperature.

\subsubsection{Radiation heat loss}

The total radiation heat loss rate from the receiver aperture can be calculated with Eq. (13):

$\dot{Q}_{l o s s, r a d}=8 \sigma A_{a p}\left(T_{s, a v e}^{4}-T_{\infty}^{4}\right)$

The view factor is important when determining the temperature profile on the receiver tube. The receiver is built up with a stainless steel tube. When calculating the temperature profile, the radiation heat loss rate and heat gain rate at different sections of the inner wall are determined with the use of Eq. (14):

$\dot{Q}_{n}=A_{n} \sum_{j=1}^{N} F_{n-j}\left(\varepsilon_{n} \sigma T_{s, n}^{4}-\varepsilon_{j} \sigma T_{s, j}^{4}\right)$ 
A surface coating is often used to create low emissivity for low radiation heat loss. From the literature, many different coatings are available [58-61]. Most of these coatings cannot operate at the high temperatures studied in this paper. The use of black chromium (with high absorptivity and low emissivity) is not recommended on components subjected to temperatures in excess of $700{ }^{\circ} \mathrm{C}[62]$.

For steel containing high chromium, emissivity is usually lower because of the chromium oxide protection layer. The emissivity value becomes fairly constant after an initial three-hour heating during which the surface oxidation becomes fully developed [63]. Thus, when a polished stainless steel tube is exposed to high temperatures, it will eventually become highly oxidised and have emissivity of 0.7 or lower [64, 65]. According to [66], types 309, 310 or 446 stainless steels are most suitable for high operating temperatures. Types 310 and 314 are also recommended by [67] as they offer good scaling resistance. The absorptance of oxidised stainless steel at $100{ }^{\circ} \mathrm{C}$ can be in the region of $0.85-0.9$ while the emitance is in the region of only $0.1-0.2$ [68]. Absorptivity and emissivity for different stainless steels at different temperatures are available from the literature $[63,69-72]$.

\subsubsection{Convection heat loss}

For convection heat loss, the available heat loss models are often limited to specific cases and temperatures. According to [44], the operating temperature range used by the Koenig and Marvin heat loss model for natural convection heat loss is considerably higher (valid up to $900^{\circ} \mathrm{C}$ ) than any other heat loss model in their study. The convection heat loss rate from the open-cavity receiver is therefore determined according to the Koenig and Marvin heat loss model [15] since it was designed to model heat loss from higher-temperature receivers. The convection heat transfer coefficient for a cavity receiver will depend on its shape, the orientation of the aperture with respect to the wind direction, the wind speed as well as skirting or baffling placed around the aperture [15]. With no attempt to suppress forced convection, heat loss due to convection may be as much as three [73] to four [15] times the magnitude of natural convection heat loss in a $4.5 \mathrm{~m} / \mathrm{s}-11 \mathrm{~m} / \mathrm{s}$ wind depending on the receiver temperature. If a wind skirt is used, forced convection heat loss may be roughly twice the magnitude of the natural convection heat loss [15]. Natural convection heat loss is the highest when the receiver aperture face is in the vertical plane and negligible when the aperture is facing straight down. Overall, the effects of wind on convection heat loss are the greatest for wind blowing parallel to the aperture and the smallest for wind blowing directly into the aperture [73]. When the aperture is facing opposite to the wind direction, convection heat loss is not much higher than for natural convection heat loss [15].

The convection heat loss rate from the open-cavity receiver surface is determined from [15] as follows:

$$
N u_{c a v}=h L / k=0.52 B(\theta)\left(G r_{L} \operatorname{Pr}\right)^{1 / 4}
$$


where

$B(\theta)=\cos ^{3.2} \theta$ if $0^{\circ} \leq \theta \leq 45^{\circ}, B(\theta)=0.707 \cos ^{2.2} \theta$ if $45^{\circ} \leq \theta \leq 90^{\circ}$

and

$G r_{L}=L^{3} g \beta\left(T_{s}-T_{\infty}\right) / v^{2}$

with

$L=\sqrt{\frac{2 a^{2}}{\pi}}$

$\beta=1 / T_{\text {prop }}$

$T_{\text {prop }}=11 / 16 T_{s}+3 / 16 T_{\infty}$

The convection heat loss rate from the open-cavity receiver aperture is calculated with Eq. (21):

$\dot{Q}_{\text {loss }, \text { conv }}=9 h A_{a p}\left(T_{s, a v e}-T_{\infty}\right)$

Similarly, the convection heat loss rate from each tube section is calculated with Eq. (22):

$\dot{Q}_{l o s s, c o n v, n}=h_{n} A_{n}\left(T_{s, n}-T_{\infty}\right)$

\subsubsection{Pressure drop}

For a fixed receiver aperture area, the larger the receiver tube diameter, the shorter the tube length will be and the smaller the pressure drop. A larger receiver tube diameter will also result in a smaller pressure drop due to bends since, 
for the shorter tube, less bends or corners will be required to construct the rectangular cavity receiver. The pressure drop through the tube is calculated as $[53,74]$ :

$$
\begin{aligned}
& \Delta P=\frac{\rho V_{a v e}^{2}}{2}\left(f \frac{L}{d}+\sum_{y} K_{y}\right) \\
& \Delta P=\frac{\rho\left(\frac{4 \dot{m}}{\rho \pi d^{2}}\right)^{2}}{2}\left(f \frac{L}{d}+\sum_{y} K_{y}\right) \\
& \Delta P=\frac{8 \dot{m}^{2}}{\rho \pi^{2} d^{4}}\left(f \frac{L}{d}+\sum_{y} K_{y}\right)
\end{aligned}
$$

where $f$ is determined from the Colebrook equation [75] for rough stainless steel and the $K$-values are determined from [74] for standard $90^{\circ}$ bends, available for the specific tube diameter being studied.

\section{Methodology and numerical methods}

\subsection{Preliminary study}

Firstly, a preliminary study is done to determine the optimum receiver aperture area vs. the dish concentrator area, $A^{\prime}$. The efficiency of the optical capturing of solar power depends on this ratio. In addition, the reflectivity of the dish is assumed $100 \%$ to keep the data relevant for different concentrator reflectivities. In the preliminary study, the receiver surface temperature is assumed to be constant at $1150 \mathrm{~K}$, so that the average heat loss rate from the entire cavity receiver can be determined. It is assumed that the net heat transfer rate and heat loss rate from the receiver are functions of the area ratio, $A^{\prime}$. Note that some of the equations were reduced to linear equations as a function of the area ratio, $A^{\prime}$, to make the results relevant for all sizes of collectors. The largest error in making this assumption was $\mathrm{R}^{2}=0.997$ with a regression line.

\subsection{Method to determine receiver tube surface temperatures and net heat transfer rates}

The temperature profile on the inner-cavity walls, which is the receiver tube surface, is determined by dividing the tube into a number of equally sized sections. The temperature profile on the receiver walls depends on the size of the receiver and concentrator. In this paper, a concentrator diameter of $4.8 \mathrm{~m}$ is used for the analysis and the temperature 
profile of its receiver is determined. The optimum receiver size, as determined in the preliminary study, is used. The dish surface is modelled as aluminium with reflectivity of $85 \%$. The temperature profile and net heat transfer rate through the pipe can be determined as follows:

$\dot{Q}_{n e t, n}=\frac{\left(T_{s, n}-\sum_{i=1}^{n-1}\left(\frac{\dot{Q}_{n e t, i}}{\dot{m} c_{p 0}}\right)-T_{i n, 0}\right)}{\left(\frac{1}{h A_{n}}+\frac{1}{2 \dot{m} c_{p 0}}\right)}$

since the fluid temperature at the centre of a control volume under consideration is

$T_{f, n}=T_{i n, n}+\frac{T_{o u t, n}-T_{i n, n}}{2}=T_{i n, n}+\frac{\dot{Q}_{n e t, n}}{2 \dot{m} c_{p 0}}$

and

$\dot{Q}_{n e t, n}=h A_{n}\left(T_{s, n}-T_{f, n}\right)$

where $T_{i n, 0}$ is the temperature of the air at the inlet of the receiver. $T_{i n, n}$ is calculated from the heat gained at the previous sections. The following set of equations is also required to solve the surface temperatures and the rates of heat transfer into the pipe at the different sections of the pipe's length. Using Eqs. (24) and (27), an equal number of equations and variables are available to be solved.

$$
\begin{aligned}
& \dot{Q}_{n e t, n}=\dot{Q}^{*}{ }_{n}-A_{n} \varepsilon_{n} \sigma\left(m_{1} T_{s, n}+c_{1}\right)+A_{n} \sum_{j=1}^{N} F_{n-j} \varepsilon_{j} \sigma\left(m_{1} T_{s, j}+c_{1}\right) \\
& -A_{n} \varepsilon_{n} \sigma F_{n-\infty} T_{\infty}^{4}-A_{n}\left(m_{2} T_{s, n}+c_{2}\right)-\frac{A_{n}}{R_{\text {cond }}}\left(T_{s, n}-T_{\infty}\right)
\end{aligned}
$$

since

$\dot{Q}_{n e t, n}=\dot{Q}^{*}{ }_{n}-\dot{Q}_{l o s s, r a d, n}-\dot{Q}_{l o s s, c o n v, n}-\dot{Q}_{l o s s, c o n d, n}$ 


$$
\begin{aligned}
& \dot{Q}_{n e t, n}=\dot{Q}^{*}{ }_{n}-A_{n} \sum_{j=1}^{N} F_{n-j}\left(\varepsilon_{n} \sigma T_{s, n}^{4}-\varepsilon_{j} \sigma T_{s, j}^{4}\right)-A_{n} F_{n-\infty}\left(\varepsilon_{n} \sigma T_{s, n}^{4}-\varepsilon_{j} \sigma T_{\infty}^{4}\right) \\
& -h_{n} A_{n}\left(T_{s, n}-T_{\infty}\right)-A_{n}\left(T_{s, n}-T_{\infty}\right) / R_{\text {cond }}
\end{aligned}
$$

Using Gaussian elimination and MATLAB, the surface temperatures $\left(T_{s, n}\right)$ and net heat transfer rates $\left(\dot{Q}_{n e t, n}\right)$ can be obtained. For heat loss to other tubes, in the range between $1000 \mathrm{~K}$ and $1300 \mathrm{~K}$, it is assumed that $T_{s, n}^{4}$ (see Eq. (29)) is a linear function of $T_{s, n}$ (see Fig. 5) in the form of $m_{l} T_{s, n}+c_{l}$ (see Eq. (27)). For convection heat loss from surface temperatures between $900 \mathrm{~K}$ and $1350 \mathrm{~K}$, a linear function for the heat loss rate was also determined and used in the analysis. The largest error in making these assumptions was $\mathrm{R}^{2}=0.988$. These heat loss functions had to be linearised so that simple Gaussian elimination could be used to determine the surface temperatures and net heat transfer rates at each section of the receiver tube wall.

The conductivity of the stainless steel tube at the considered temperatures is assumed to be $30 \mathrm{~W} / \mathrm{mK}$ [67], and thus the thermal resistance due to conductivity through the tube wall of $2 \mathrm{~mm}$ thickness is neglected.

\subsection{Entropy generation rate}

The entropy generation rate in the open-cavity receiver of a solar thermal Brayton cycle (see [2-5]) is determined with the following equation:

$$
\dot{S}_{\text {gen }}=-\frac{\dot{Q}^{*}}{T^{*}}+\frac{\dot{Q}_{\text {loss }}}{T_{s, \text { ave }}}+\dot{m} c_{p 0} \ln \left(\frac{T_{\text {out }}}{T_{\text {in }}}\right)-\dot{m} R \ln \left(\frac{P_{\text {out }}}{P_{\text {in }}}\right)
$$

Equation (31) gives a good indication of how the receiver would perform in the solar thermal Brayton cycle

$$
\eta_{2 \text { ndLaw }}=\frac{\left(1-\frac{T_{\infty}}{T^{*}}\right) \dot{Q}^{*}+\frac{T_{\infty} \dot{Q}^{*}}{T^{*}}-\frac{T_{\infty} \dot{Q}_{\text {loss }}}{T_{s, a v e}}-T_{\infty} \dot{m} c_{p 0} \ln \left(\frac{T_{\text {out }}}{T_{\text {in }}}\right)+T_{\infty} \dot{m} R \ln \left(\frac{P_{\text {out }}}{P_{\text {in }}}\right)}{\left(1-\frac{T_{\infty}}{T^{*}}\right) \dot{Q}^{*}}
$$


where $T^{*}$ is assumed to be equal to $4350 \mathrm{~K}$ [5] and $P_{\text {in }}=180 \mathrm{kPa}[4]$.

\section{Results and discussion}

\subsection{Preliminary results}

Figures 6 and 7 show the solar power available at the aperture of a rectangular open-cavity receiver, relative to the solar power available after being concentrated at the dish, as determined with SolTrace. The results show that, for small optical errors, the optimum area ratio increases as the tracking error increases. Note that these results should still be multiplied with the reflectivity of the concentrator dish and $\dot{Q}_{\text {solar }}$ to determine the available solar power at the receiver aperture. These results are valid for all sizes of dish collectors.

By assuming an average receiver surface temperature of $1150 \mathrm{~K}$ in the preliminary study, the heat losses from the receiver due to conduction, radiation and convection were determined. Figures $8-11$ show the overall receiver efficiency, which is the product of the optical efficiency and the receiver efficiency as shown in Eq. (2). Figure 10 shows the effect of surface emissivity. It shows that a much higher overall receiver efficiency could be expected if a high-temperature surface coating was available with emissivity of only 0.2 . For a tracking error of $1^{\circ}$ and an optical error of $10 \mathrm{mrad}$, the optimum area ratio for a rectangular open-cavity receiver with parabolic dish is determined from Fig. 9. An optimum ratio of $A^{\prime} \approx 0.0035$ is identified from Fig. 9, where the accompanying optical efficiency is $92.3 \%$ (see Fig. 7). Note that $A^{\prime}$ is the optimum ratio of receiver aperture area to concentrator aperture area. Also note that this is an optimum for a concentrator rim angle of $45^{\circ}$, tracking error of $1^{\circ}$, optical error of 10 mrad, average receiver surface temperature of $1150 \mathrm{~K}$, receiver surface emissivity of $0.7,0.1 \mathrm{~m}$ ceramic fibre insulation thickness and an assumed average wind speed of $2.5 \mathrm{~m} / \mathrm{s}$. This optimum area ratio is, however, also valid for a surface emissivity of 0.2 (see Fig. 10). In addition, note that the results should still be multiplied with the reflectance of the concentrator dish surface and $\dot{Q}_{\text {solar }}$ to determine the total net heat transfer rate in the receiver.

The optimum ratio found is valid for all sizes of dish concentrators. The optimum ratio can be compared with the optimum ratios of $A^{\prime} \approx 0.0007[76], 0.0004 \leq A^{\prime} \leq 0.0009[15]$ and $A^{\prime} \approx 0.00024$ [22] found in the literature. The optimum ratio found by [15] and [76] is much smaller than found in this work because of more accurate optics assumed in their studies - tracking error is not included in their studies, thus the tracking error is $0^{\circ}$. The results found by [15] do, however, compare well with the optimum area ratio found in Fig. 8 for a tracking error of $0^{\circ}$ and optical error of 5 mrad. [22] also found a much smaller optimum ratio, since their silicon carbide receiver operates at a much higher temperature, which would intensify heat loss significantly. 
Figure 11 shows the effect of a tracking error of $2^{\circ}$ with a surface emissivity of 0.2 . For a surface emissivity of 0.7 and $2^{\circ}$ tracking error, the overall receiver efficiency is very low (less than 20\%) and is not shown. A tracking error of more than $1^{\circ}$ is thus not favourable.

\subsection{Receiver solar heat flux profile}

In the previous section, results showed that an optimum area ratio of $A^{\prime}=0.0035$ can be used for a system with tracking error of $1^{\circ}$ and $10 \mathrm{mrad}$ optical error. For this optimum area ratio, tracking error and optical error, the solar heat flux rate at the different parts of the different walls of the receiver is shown in Figs. 12 and 13, as was found with SolTrace. These results were obtained by assuming that the inner walls of the cavity receiver were flat surfaces. Note that these solar heat flux rates are for a parabolic concentrator rim angle of $45^{\circ}$. Also note that the results should be multiplied with the reflectance of the concentrator dish to determine the available solar heat flux rate at the receiver inner walls. A

solar beam irradiance of $I=1000 \mathrm{~W} / \mathrm{m}^{2}$ was used to generate the results. Note that $\dot{Q}_{\text {solar }}=I \pi D_{\text {conc }}^{2} / 4$. The results are also valid for different solar beam irradiances if multiplied with the beam irradiance ratio. These solar heat flux rates are valid for all sizes of open rectangular cavity receivers with the ratio of $A^{\prime} \approx 0.0035$. The results show that the higher the tracking error, the larger the heat flux rate at the bottom parts of the one side of the receiver.

\subsection{Temperature profile and net heat transfer rate of receiver tube}

The receiver surface temperature at the different positions of the tube and the net heat transfer rate available for air heating will depend on the receiver size, mass flow rate through the receiver, receiver tube diameter, receiver inlet temperature and dish reflectivity. Thus, a receiver with aperture of $0.25 \mathrm{~m}$ x $0.25 \mathrm{~m}$ and a dish concentrator diameter of $4.8 \mathrm{~m}$ with $85 \%$ reflectivity was chosen. The depth of the receiver is $0.5 \mathrm{~m}$, as the receiver is rectangular. The results were found in MATLAB by solving Eqs. (24) and (27) simultaneously using Gaussian elimination. The view factors for the different tube sections are shown in Tables 2, 3 and 4, as determined with view factor relations available from [53]. Note that, for the analysis, the receiver tube of the rectangular cavity is divided into a number of sections as determined with Eq. (32):

$N=4(2 a / d)+a / d=9 a / d$ 
The results shown in Fig. 14 and Fig. 15 give the tube surface temperature and net heat transfer rate at the different positions of a $0.05 \mathrm{~m}$ diameter tube used in an open-cavity rectangular receiver with square aperture side length of $a=0.25 \mathrm{~m}$ and an inlet temperature of $1070 \mathrm{~K}$. The increase in fluid temperature is also shown. A mass flow rate of $0.07 \mathrm{~kg} / \mathrm{s}$ is used. The overall collector efficiency, $\eta_{c o l}$, for $0^{\circ}$ tracking error is $44 \%$ whereas, for a tracking error of $1^{\circ}$, the overall collector efficiency is $39 \%$. This efficiency can be improved by improving the reflectance of the concentrator, by changing the receiver design or surface coating or by altering the mass flow rate, inlet temperature and tube diameter. Note that for $A^{\prime} \approx 0.0035$, the accompanying optical efficiency at $0^{\circ}$ tracking error is $99.6 \%$ and at $1^{\circ}$ tracking error, the optical efficiency is $92.3 \%$ (see Fig. 6 and Fig. 7). The optimum system mass flow rate for a solar thermal Brayton cycle as a function of concentrator diameter was found by [2] and can be approximated with Eq. (33):

$\dot{m}_{\text {opt }} \approx-0.0002 D_{\text {conc }}^{3}+0.0097 D_{\text {conc }}^{2}-0.0626 D_{\text {conc }}+0.1773$

For a tube diameter of $0.0833 \mathrm{~m}$, a mass flow rate of $0.08 \mathrm{~kg} / \mathrm{s}$ and an inlet temperature of $1000 \mathrm{~K}$, the results are shown in Fig. 16 and 17. These results are very similar to those presented in Fig. 14 and 15, except for the higher net heat transfer rates and lower temperatures.

Tables 5 - 7 show the effects of mass flow rate, receiver tube air inlet temperature and tube diameter on the efficiency of the receiver (net heat transfer rate vs. available solar power), pressure drop, and maximum receiver surface temperature. The receiver performance can be compared with the efficiencies of other solar receivers from the literature (Table 1). It is concluded that the higher the inlet temperature, the less efficient the receiver becomes and the higher the maximum receiver surface temperature. For the tracking error of $1^{\circ}$, the receiver efficiency and average surface temperature are less. For higher efficiency, lower inlet temperatures are beneficial so that lower surface temperatures are present; however, for the Brayton cycle, a larger outlet temperature would be beneficial. Thus, a high receiver efficiency is not necessarily beneficial for the system as a whole. It is also concluded that the higher the mass flow rate, the lower the surface temperatures and the more efficient the receiver. This was also found in the literature by [18] and [19]. Again, note that a higher mass flow rate is not necessarily beneficial for the system as a whole, since the pressure drop increases and the outlet temperature decreases.

\subsection{Effect of wind}

The net heat transfer rate and tube surface temperature profile are affected by the wind, as shown in Fig. 18, by assuming that the convection heat transfer coefficient is roughly 10 times the natural convection heat transfer 
coefficient. The collector efficiency comes down to $10 \%$, which shows that the effect of wind should be considered when modelling the cavity receiver.

\subsection{Entropy generation rate due to the solar receiver}

The second law efficiency is presented in Tables $5-7$ as a function of mass flow rate and receiver tube size. The entropy generation rate as shown in Eq. (30) can be used in an optimisation equation such as given by [5] to determine the best receiver tube size, recuperator geometry and micro-turbine to be used in a small-scale solar thermal Brayton cycle for maximum net power output. The second law efficiency can be used as an indicator when choosing a receiver tube diameter. In Tables $5-7, \eta_{2 n d L a w}$ increases as $d$ and $T_{i n, 0}$ increase while $\eta_{\text {rec }}$ decreases, indicating that a large tube diameter is beneficial in a small-scale solar thermal Brayton cycle. The smaller tube diameter allows for higher efficiency but due to the high pressure drop, a much lower second law efficiency is obtained and indicates that a larger tube would be more beneficial. As the mass flow rate increases, $\eta_{\text {rec }}$ increases, while $\eta_{2 \text { ndLaw }}$ decreases or stays constant when the tube diameter is large. The highest $\eta_{2 n d L a w}$ was found when the tube diameter and inlet temperature are large and mass flow rate is small. However, these variables would also create a very high surface temperature. If the surface temperature is restricted to $1200 \mathrm{~K}$, a larger mass flow rate and lower inlet temperature can still provide high second law efficiencies, when a large tube diameter is used.

\section{Conclusion}

Heat loss from a proposed closed-tube open-cavity solar receiver made of stainless steel was modelled. This solar receiver is used in a small-scale solar thermal Brayton cycle using a micro-turbine with small compressor pressure ratios. From the results given, the optimum receiver aperture area can be determined for any dish size, tracking error and optical error. An optimum receiver-to-concentrator-area ratio of $A^{\prime} \approx 0.0035$ was found in this paper for a concentrator with $45^{\circ}$ rim angle, $1^{\circ}$ tracking error and $10 \mathrm{mrad}$ optical error. These errors are allowed for dish misalignment, manufacturing and installation. A method to determine the temperature profile and net heat transfer rate profile of the receiver tube was also presented. For a $4.8 \mathrm{~m}$ diameter dish with optimised receiver aperture area of $A^{\prime}=$ 0.0035 , it was shown that the larger the receiver tube and the smaller the mass flow rate, the higher the receiver surface temperature and the less efficient the collector becomes. However, the smaller the receiver tube, the higher the pressure drop through the tube and the higher the entropy generation rate. The larger tube diameters will, however, have a lower pressure drop, which can be much more valuable when used in the solar thermal Brayton cycle. Furthermore, it was 
shown that the receiver efficiency can be upgraded by increasing the dish reflectivity by using a high-temperature receiver coating with low emissivity and by increasing the accuracy of the optics and dish surface. Future work would consist of the experimental testing of such a receiver for comparison with the results found. The efficiencies found in this work compare well with other solar receivers from the literature. The limiting factor on maximum second law efficiency is the receiver surface temperature. Receivers are often designed to give high exit temperature and high efficiency; however, the work showed that the second law efficiency, or the ability of the receiver to be combined with the solar thermal Brayton cycle, is more important.

\section{Acknowledgement}

This work is based on the research supported by the National Research Foundation (NRF), University of Pretoria, CRSES, the Solar Hub between the University of Pretoria and Stellenbosch University, TESP, NAC, EEDSH Hub, Energy-IRT and the CSIR. The financial assistance of the National Research Foundation (NRF) towards this research is hereby acknowledged. Opinions expressed and conclusions arrived at are those of the authors and are not necessarily to be attributed to the NRF. The authors also acknowledge Suzanne E. Roberts and Bera K. Chirwa (University of Pretoria) for their contributions at the initial stage of this paper.

\section{References}

[1] Pietsch A, Brandes DJ. Advanced solar Brayton space power systems. In: Proceedings of intersociety energy conversion engineering conference, IECEC, Los Alamitos, CA; 1989. p. 911-6.

[2] Le Roux WG, Bello-Ochende T, Meyer JP. Operating conditions of an open and direct solar thermal Brayton cycle with optimised cavity receiver and recuperator. Energy 2011;36:6027-36.

[3] Le Roux WG, Bello-Ochende T, Meyer JP. Thermodynamic optimisation of an integrated design of a small-scale solar thermal Brayton cycle. International Journal of Energy Research 2012;36:1088-104.

[4] Le Roux WG, Bello-Ochende T, Meyer JP. Optimum performance of the small-scale open and direct solar thermal Brayton cycle at various environmental conditions and constraints. Energy 2012;46:42-50.

[5] Le Roux WG, Bello-Ochende T, Meyer JP. A review on the thermodynamic optimisation and modelling of the solar thermal Brayton cycle. Renewable and Sustainable Energy Reviews 2013;28:677-90.

[6] Mills D. Advances in solar thermal electricity technology. Solar Energy 2004;76:19-31. 
[7] Kaushik SC, Tyagi SK. Finite time thermodynamic analysis of an irreversible regenerative closed cycle Brayton heat engine. International Journal of Solar Energy 2002;22(3-4):141-51.

[8] Tyagi SK, Chen J, Kaushik SC. Optimal criteria based on the ecological function of an irreversible intercooled regenerative modified Brayton cycle. International Journal of Exergy 2005;2(1):90-107.

[9] Tyagi SK, Chen GM, Wang Q, Kaushik SC. Thermodynamic analysis and parametric study of an irreversible regenerative-intercooled-reheat Brayton cycle. International Journal of Thermal Sciences 2006;45:829-40.

[10] Gandhidasan P. Thermodynamic analysis of a closed-cycle solar gas-turbine plant. Energy Conversion and Management 1993;34(8):657-61.

[11] Ávila-Marín AL. Volumetric receivers in solar thermal power plants with central receiver system technology: a review. Solar Energy 2011;85:891-910.

[12] Ho CK, Iverson BD. Review of high-temperature central receiver designs for concentrating solar power. Renewable and Sustainable Energy Reviews 2014;29:835-46.

[13] Hunt AJ. A new solar thermal receiver utilizing a small particle heat exchanger. In: Proceedings of the 13th intersociety energy conversion engineering conference, August, Boston, MA; 1979. p. 5-10.

[14] Stine BS, Harrigan RW. Solar energy fundamentals and design. New York: John Wiley \& Sons; 1985.

[15] Harris JA, Lenz TG. Thermal performance of solar concentrator/cavity receiver systems. Solar Energy $1983 ; 34(2): 135-42$.

[16] Cameron HM, Mueller LA, Namkoong D. Preliminary design of a solar heat receiver for a Brayton-cycle space power system. Report NASA TM X-2552, National Aeronautics and Space Administration, Lewis Research Center; 1972.

[17] Cui H, Hou X, Yuan X. Energy analysis of space solar dynamic heat receivers. Solar Energy 2003;74:303-8.

[18] Kribus A, Doron P, Rubin R, Karni J, Reuven R, Duchan S, Taragan E. A multistage solar receiver: the route to high temperature. Solar Energy 1999;67(1-3):3-11.

[19] Hischier I, Hess D, Lipiński W, Modest M, Steinfeld A. Heat transfer analysis of a novel pressurized air receiver for concentrated solar power via combined cycles. Journal of Thermal Science and Engineering Applications 2009;1:041002-1-6.

[20] Fork DK, Fitch J, Ziaei S, Jetter RI. Life estimation of pressurized-air solar-thermal receiver tubes. Journal of Solar Energy Engineering 2012;134(4): 041016-1-11.

[21] Heller P, Pfänder M, Denk T, Tellez F, Valverde A, Fernandez J, Ring A. Test and evaluation of a solar powered gas turbine system. Solar Energy 2006;80:1225-30.

[22] Neber M, Lee H. Design of a high temperature cavity receiver for residential scale concentrated solar power. Energy 2012;47:481-7. 
[23] Shuai Y, Xia X, Tan H. Radiation performance of dish solar concentrator/cavity receiver systems. Solar Energy $2008 ; 82: 13-21$.

[24] Cui F, He Y, Cheng Z, Li Y. Study on combined heat loss of a dish receiver with quartz glass cover. Applied Energy 2013;112:690-6.

[25] Gianella S. Porous materials for high-temperature solar absorbers. International Symposium on High Temperature Solar Materials, Yeungnam University, Korea; 2012.

[26] Aichmayer L. Solar receiver design and verification for small scale polygeneration unit. Thesis: Graz University of Technology, Austria, EGI-2011-119MSC-EKV862, Stockholm, Sweden; 2011.

[27] Karni J, Kribus A, Doron P, Rubin R, Filterman A, Sagie D. The DIAPR: a high-pressure high-temperature solar receiver. Journal of Solar Energy Engineering 1997;119:74-78.

[28] Buck R, Bräuning T, Denk T, Pfänder M, Schwarzbözl P, Tellez F. Solar-hybrid gas turbine-based power tower systems (REFOS). Journal of Solar Energy Engineering 2002;124:1-9.

[29] Amsbeck L, Denk T, Ebert M, Gertig C, Heller P, Herrmann P, Jedamski J, John J, Pitz-Paal R, Prosinečki T, Rehn J, Reinalter, Uhlig R. Test of a solar-hybrid microturbine system and evaluation of storage deployment. In: Proceedings of solarPACES international symposium of solar thermal, September, Perpignan, France; 2010.

[30] Quero M, Korzynietz R, Ebert M, Jiménez AA, del Río A, Brioso JA. Solugas - operation experience of the first solar hybrid gas turbine system at MW scale. In: Proceedings of solarPACES international symposium of solar thermal; 2013.

[31] Helwa NH, Bahgat ABG, El Shafee AMR, El Shenawy ET. Maximum collectable solar energy by different solar tracking systems. Energy Sources 2000;22(1):23-34.

[32] Brooks MJ. Performance of a parabolic trough solar collector. Dissertation: University of Stellenbosch; 2005.

[33] Naidoo P, Van Niekerk TI. Optimising position control of a solar parabolic trough. S Afr J Sci 2011;107(3/4):452.

[34] Chong KK, Wong CW. General formula for on-axis sun-tracking system and its application in improving tracking accuracy of solar collector. Solar Energy 2009;83:298-305.

[35] Al-Naima FM, Yaghobian NA. Design and construction of a solar tracking system. Solar \& Wind Technology 1990;7(5):611-7.

[36] Argeseanu A, Ritchie E, Leban K. A new solar position sensor using low cost photosensors matrix for tracking systems. WSEAS Transactions on Power Systems 2009;64:189-98.

[37] Stafford B, Davis M, Chambers J, Martínez M, Sanchez D. Tracker accuracy: field experience, analysis, and correlation with meteorological conditions. In: Proceedings of the $34^{\text {th }}$ photovoltaic specialists conference; 2009.

[38] Janecek M, Moses WM. Optical reflectance measurements for commonly used reflectors. IEEE Transactions on Nuclear Science 2008;55(4):2432-7. 
[39] BASF, The Chemical Company. Pigment for solar heat management in paints; 2007. Available at: Www.basf.com/pigment [Last accessed on 2013/10/07].

[40] Grossman JW, Houser RM, Erdman WW. Prototype dish testing and analysis at Sandia National Laboratories. Sandia Laboratory Report SAND91-1283C; 1991.

[41] Gee R, Brost R, Zhu G, Jorgensen G. An improved method for characterizing reflector specularity for parabolic trough concentrators. In: Proceedings of solarPACES international symposium of solar thermal, September, Perpignon, France, 0284; 2010.

[42] SolarPACES Guidelines. Measurement of solar weighted reflectance of mirror materials for concentrating solar power technology with commercially available instrumentation. Interim Version 1.1, May; 2011.

[43] Bode SJ, Gauché P. Review of optical software for use in concentrated solar power systems. In: Proceedings of the Southern African Solar Energy Conference, SASEC, May, Stellenbosch, South Africa; 2012.

[44] McDonald CG. Heat loss from an open cavity. Sandia Laboratory Report SAND95-2939; 1995.

[45] Jilte RD, Kedare SB, Nayak JK. Natural convection and radiation heat loss from open cavities of different shapes and sizes used with dish concentrator. Mechanical Engineering Research 2013;3(1):25-43.

[46] Xin S, Le Quéré P. Natural-convection flows in air-filled, differentially heated cavities with adiabatic horizontal walls. Numerical Heat Transfer Part A 2006;50(5):437-66.

[47] Nogueira RM, Martins MA, Ampessan F. Natural convection in rectangular cavities with different aspect ratios. Thermal Engineering 2011;10(01-02):44-9.

[48] Prakash M. Numerical studies on natural convection heat losses from open cubical cavities. Journal of Engineering 2013;320647:1-9.

[49] Clausing AM. An analysis of convective losses from cavity solar central receivers, Solar Energy 1981;27(4):295300.

[50] Sendhil Kumar N, Reddy KS. Comparison of receivers for solar dish collector system. Energy Conversion and Management 2008;49:812-9.

[51] Vasseur P, Robillard L. Natural convection in a rectangular cavity with wall temperature decreasing at a uniform rate. Wärme- und Stoffübertragung 1982;16:199-207.

[52] Saitoh T, Hirose K. High-accuracy bench mark solutions to natural convection in a square cavity. Computational Mechanics 1989;4:417-27.

[53] Çengel YA. Heat and mass transfer. $3^{\text {rd }}$ Edition. McGraw-Hill: Nevada; 2006

[54] Zukauskas A. Convection heat transfer in cross flow. Advances in Heat Transfer 1972;8:93-106.

[55] Churchill SW, Chu HHS. Correlating equations for laminar and turbulent free convection from a vertical plate. International Journal of Heat Mass Transfer 1975;18:1323. 
[56] Lloyd JR, Sparrows EM. Combined force and free convection flow on vertical surfaces. International Journal of Heat Mass Transfer 1970;13.

[57] Wallis RA. The thermal performance of an Ultra High Power (UHP) electrical furnace for the reheating of steel slabs, Appendix A, Properties of High Temperature Ceramic Fibres. Thesis: Cranfield Institute of Technology; 1989.

[58] Lampert CM. Coatings for enhanced photothermal energy collection. Solar Energy Materials 1979;1:319-41.

[59] Hutchins MG. Spectrally selective solar absorber coatings. Applied Energy 1979;5(4):251-262.

[60] Bogaerts WF, Lampert CM. Review materials for photothermal solar energy conversion, Journal of Materials Science 1983;18:2847-75.

[61] Ambrosini A, Lambert TN, Staiger CL, Hall AC, Bencomo M, Stechel EB. Improved high temperature solar absorbers for use in concentrating solar power central receiver applications. Sandia Laboratory Report SAND2010-7080; 2010.

[62] Mandich NV, Snyder DL. Modern electroplating. 5th Edition. John Wiley \& Sons; 2010.

[63] Wen C. Investigation of steel emissivity behaviors: examination of Multispectral Radiation Thermometry (MRT) emissivity models. International Journal of Heat and Mass Transfer 2010;53:2035-43.

[64] Bogaard RH, Desai PD, Li HH, Ho CY. Thermophysical properties of stainless steels. Thermochimica Acta $1993 ; 218: 373-93$.

[65] Richmond JC, Stewart JE. Spectral emittance of ceramic-coated and uncoated specimens of inconel and stainless steel. Journal of the American Ceramic Society 1959;42(1).

[66] NDI, Nickel Development Institute. High temperature characteristics of stainless steel, a designers' handbook series. 9004. American Iron and Steel Institute. Available from www.nickelinstitute.org [Accessed 2014/03/11].

[67] Outukumpu. High temperature austenitic stainless steel. Available from: www.outokumpu.com [Accessed on 2013/10/07].

[68] Valkonen E, Karlsson B. Spectral selectivity of a thermally oxidized stainless steel. Solar Energy Materials $1982 ; 7: 43-50$.

[69] Cao G, Weber SJ, Martin SO, Sridharan K, Anderson MH, Allen TR. Spectral emissivity of candidate alloys for very high temperature reactors in high temperature air environment. Journal of Nuclear Materials 2013;441:66773.

[70] Otsuka A, Hosono K, Tanaka R, Kitagawa K, Arai N. A survey of hemispherical total emissivity of the refractory metals in practical use. Energy 2005;30:535-43.

[71] Jones PD, Nisipeanu E. Spectral-directional emittance of thermally oxidized 316 stainless steel. International Journal of Thermophysics 1996;17(4):967-78. 
[72] Kobayashi M, Ono A, Otsuki M, Sakate H, Sakum F. A database of normal spectral emissivities of metals at high temperatures. International Journal of Thermophysics 1999;20(1):299-308.

[73] Ma RY. Wind effects on convective heat loss from a cavity receiver for a parabolic concentrating solar collector. Sandia Laboratory Report SAND92-7293; 1993.

[74] White FM. Fluid mechanics. $5^{\text {th }}$ Edition. McGraw-Hill: Rhode Island; 2005.

[75] Colebrook CF. Turbulent flow in pipes, with particular reference to the transition between the smooth and rough pipe laws. Journal of the Institute of Civil Engineers London 1939;11:133-56.

[76] Steinfeld A, Schubnell M. Optimum aperture size and operating temperature of a solar cavity-receiver. Solar Energy 1993;50(1):19-25.

\section{Nomenclature}

$a$

A

$A^{\prime}$

B

$c_{1}$

$c_{2}$

$c_{p 0}$

$d$

D

$f$

F

$g$

$G r$

$h$

$I$

$k$

K

$L$

$m_{1}$
Receiver aperture side length, $\mathrm{m}$

Area, $\mathrm{m}^{2}$

Area ratio $\left(A_{a p} / A_{\text {conc }}\right)$

Function of $\theta$

Constant used in linear equation

Constant used in linear equation

Constant pressure specific heat, $\mathrm{J} / \mathrm{kgK}$

Receiver tube diameter, $\mathrm{m}$

Diameter, $m$

Friction factor

View factor

Gravitational constant, $\mathrm{m} / \mathrm{s}^{2}$

Grasshof number

Heat transfer coefficient, $\mathrm{W} / \mathrm{m}^{2} \mathrm{~K}$

Direct normal solar irradiance, $\mathrm{W} / \mathrm{m}^{2}$

Thermal conductivity, $\mathrm{W} / \mathrm{mK}$

Friction loss coefficient

Length, $\mathrm{m}$

Slope of linear equation 


\begin{tabular}{|c|c|}
\hline$m_{2}$ & Slope of linear equation \\
\hline$\dot{m}$ & System mass flow rate, $\mathrm{kg} / \mathrm{s}$ \\
\hline$N$ & Number of tube sections \\
\hline$N u$ & Nusselt number \\
\hline$P$ & Pressure, $\mathrm{Pa}$ \\
\hline $\operatorname{Pr}$ & Prandtl number \\
\hline$\dot{q}$ & Heat flux rate, $\mathrm{W} / \mathrm{m}^{2}$ \\
\hline$\dot{Q}$ & Heat transfer rate, $\mathrm{W}$ \\
\hline$\dot{Q}^{*}$ & Rate of available solar heat at receiver cavity, $\mathrm{W}$ \\
\hline$\dot{Q}_{\text {loss }}$ & Rate of heat loss from the cavity receiver, $\mathrm{W}$ \\
\hline$\dot{Q}_{\text {net }}$ & Net heat transfer rate, $\mathrm{W}$ \\
\hline$R$ & Thermal resistance, $\mathrm{K} / \mathrm{W}$ \\
\hline$R$ & Gas constant, $\mathrm{J} / \mathrm{kgK}$ \\
\hline$R a$ & Raleigh number \\
\hline $\operatorname{Re}$ & Reynolds number \\
\hline$\dot{S}_{g e n}$ & Entropy generation rate, $\mathrm{W} / \mathrm{K}$ \\
\hline$t$ & Thickness, m \\
\hline$T$ & Temperature, $\mathrm{K}$ \\
\hline$T^{*}$ & Apparent exergy-source sun temperature, $\mathrm{K}$ \\
\hline$V$ & Velocity, $\mathrm{m} / \mathrm{s}$ \\
\hline$\dot{W}$ & Power, W \\
\hline
\end{tabular}

Greek symbols

$\begin{array}{ll}\beta & \text { Coefficient of volume expansion, } 1 / \mathrm{K} \\ \varepsilon & \text { Emissivity } \\ \sigma & \text { Stefan-Boltzmann constant, } \mathrm{W} / \mathrm{m}^{2} \mathrm{~K} \\ \rho & \text { Density, } \mathrm{kg} / \mathrm{m}^{3} \\ \theta & \text { Elevation of tracking system (sun's elevation from horizontal) } \\ \eta & \text { Collector efficiency }\end{array}$




$\begin{array}{ll}v & \text { Kinematic viscosity, } \mathrm{m}^{2} / \mathrm{s} \\ \omega & \text { Error, mrad }\end{array}$

Subscripts

$0 \quad$ Initial inlet to receiver

2ndLaw As determined with the second law of thermodynamics

air Of the air

ap Aperture

ave Average

$B C \quad$ Brayton cycle

c

Compressor

cav For the cavity

col Overall for the collector

combined Combined

conc Concentrator

cond Due to conduction

conv Due to convection

f $\quad$ Fluid

forced Due to forced convection

in At the inlet

ins Insulation

$L \quad$ Based on the length

$\max \quad$ Maximum

$n \quad$ Tube section number

natural Due to natural convection

net $\quad$ Net

opt Optimum

optical Optical

out At the outlet

outer On the outside of the insulation

prop At which the properties are evaluated

rec Receiver 
refl

$\mathrm{rad}$

$R E C$

S

side1

side2

slope

solar

specularity

$S T B C$

$t$

total

$\infty$
Due to concentrator reflectivity

Due to radiation

For the receiver including optical efficiency

Surface

At the sides of the receiver in parallel with the wind direction

At the sides of the receiver normal to the wind direction

Slope

Direct normal irradiance from the sun

Specularity

Solar thermal Brayton cycle

Turbine

Total

Environment 


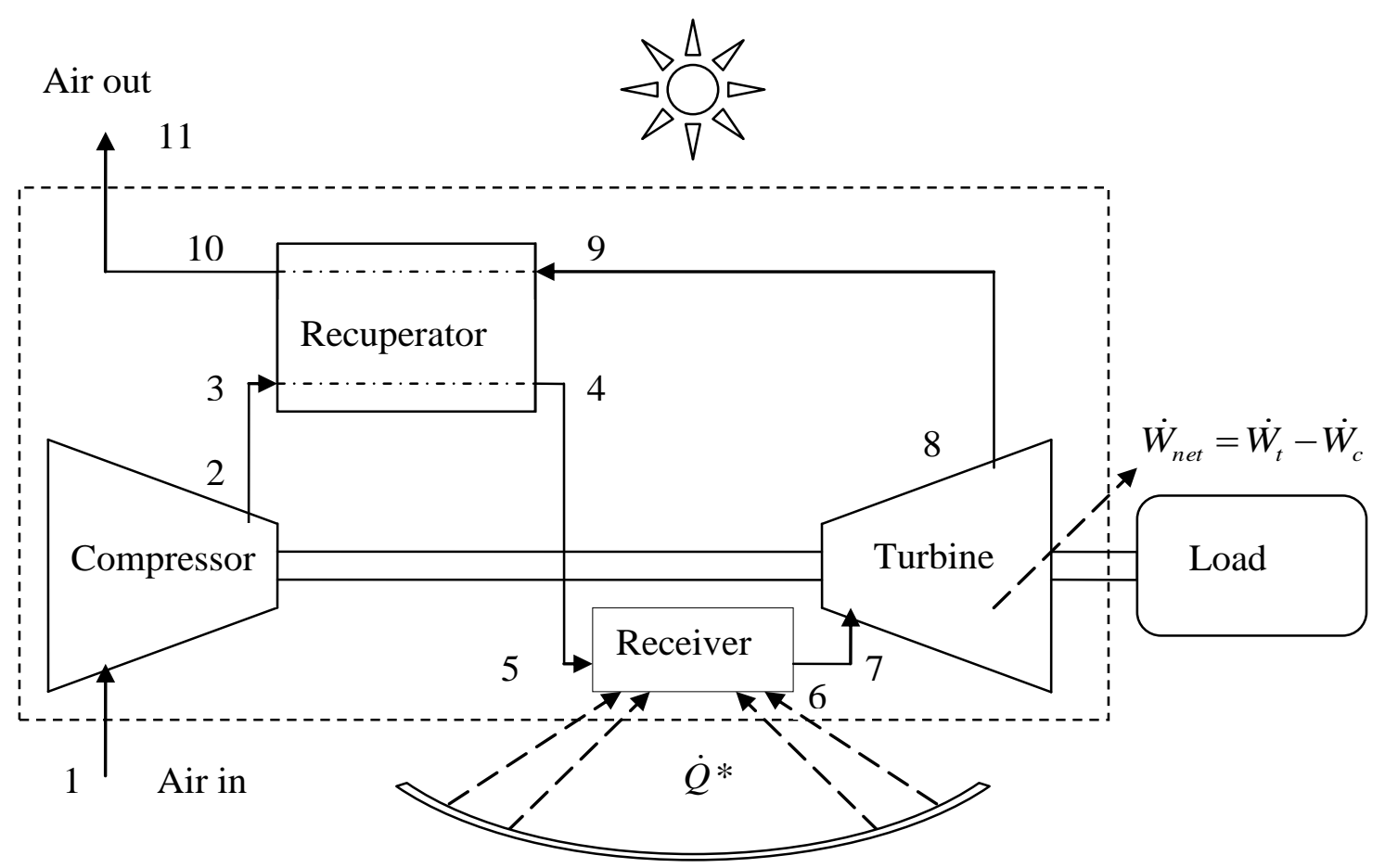

Fig. 1. The open and direct solar thermal Brayton cycle.

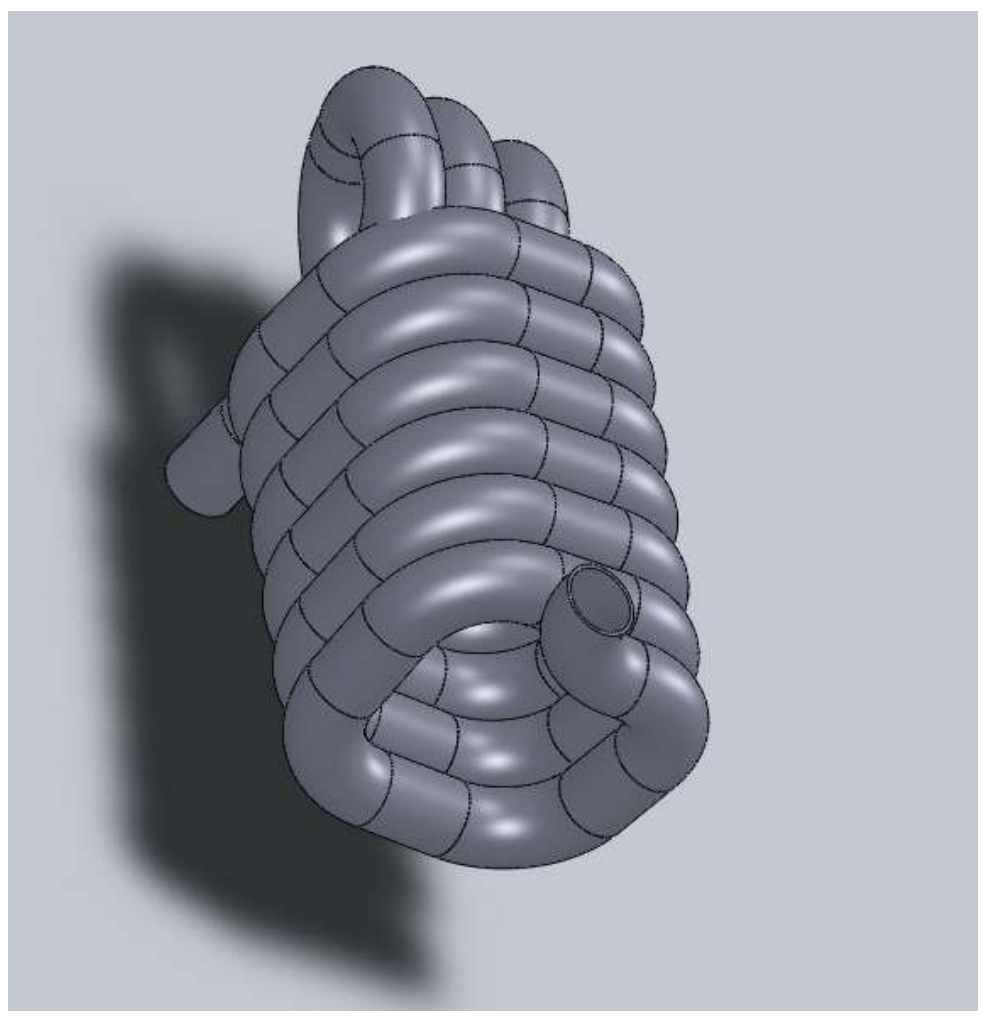

Fig. 2. A rectangular open-cavity solar receiver. 


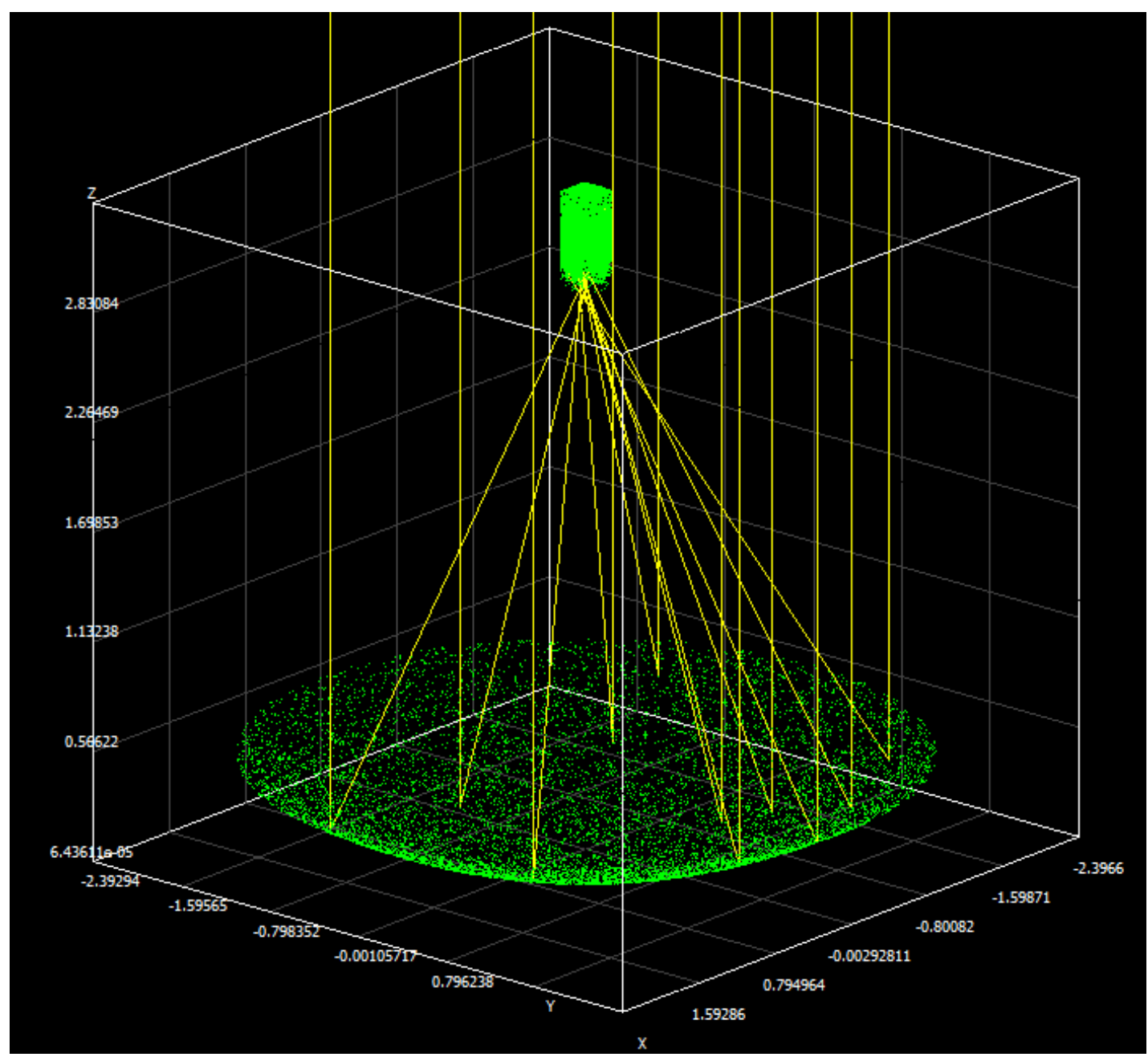

Fig. 3. Example of an analysis done in SolTrace for the solar dish and receiver.

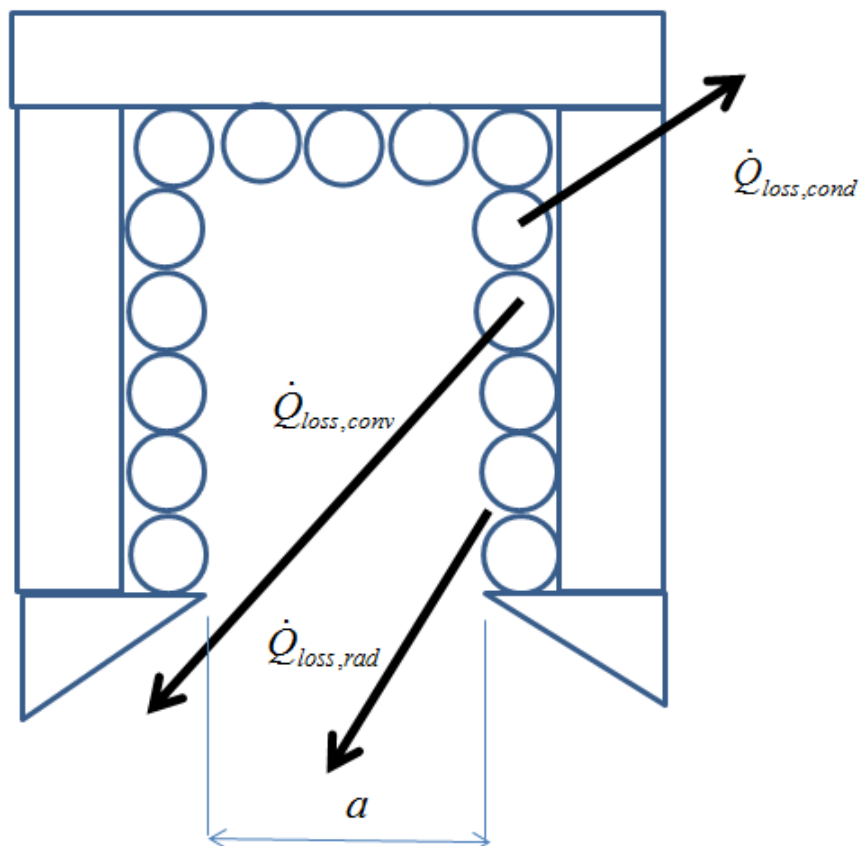

Fig. 4. Heat loss from the open-cavity receiver. 


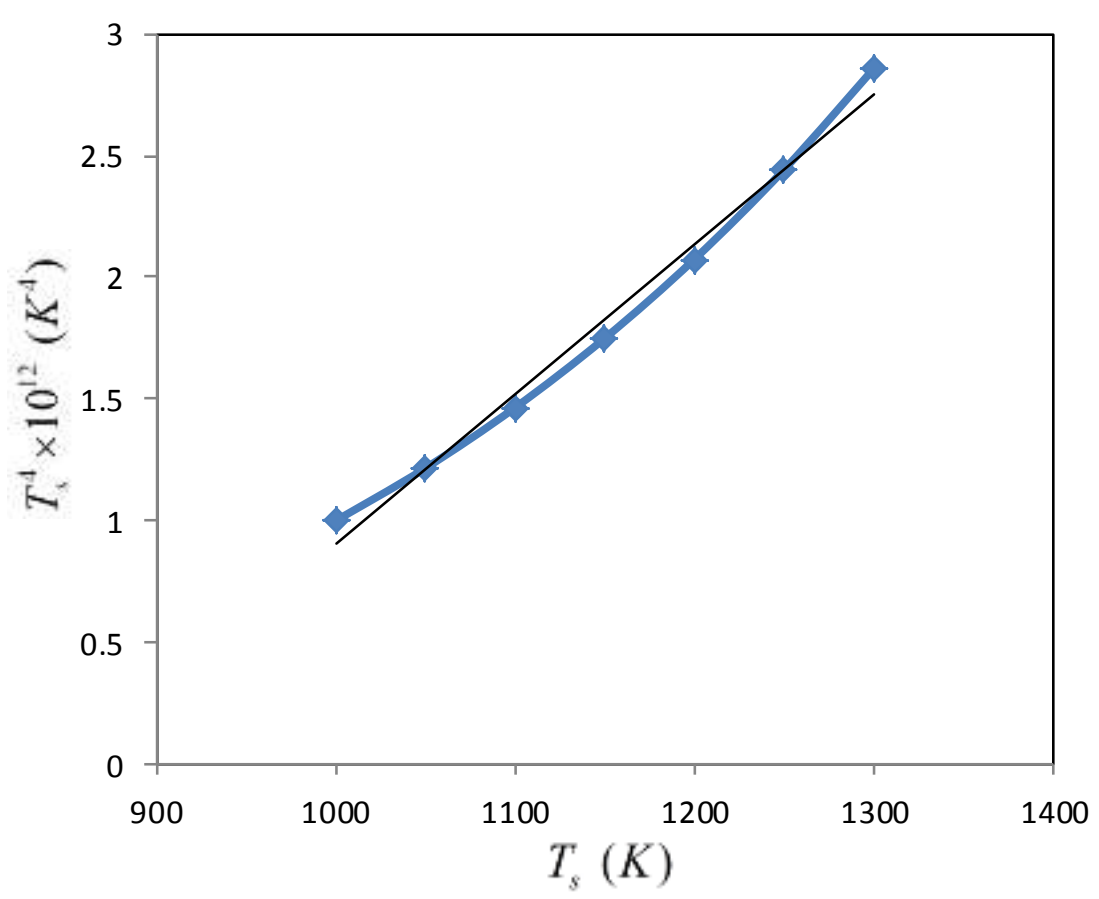

Fig. 5. Regression line for $T_{s}^{4}$ with $\mathrm{R}^{2}$-value of 0.988 .

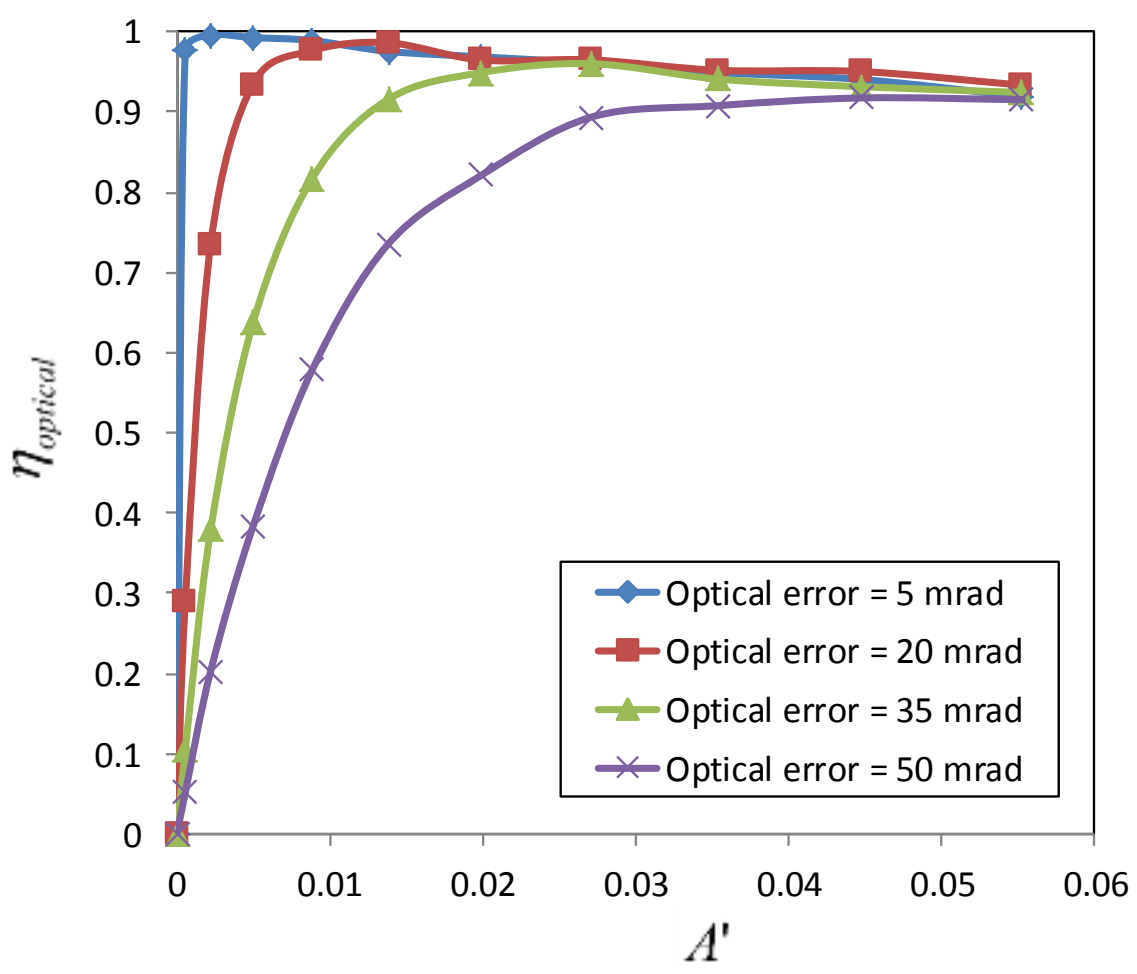

Fig. 6. Optical efficiency for a tracking error of $0^{\circ}$. 


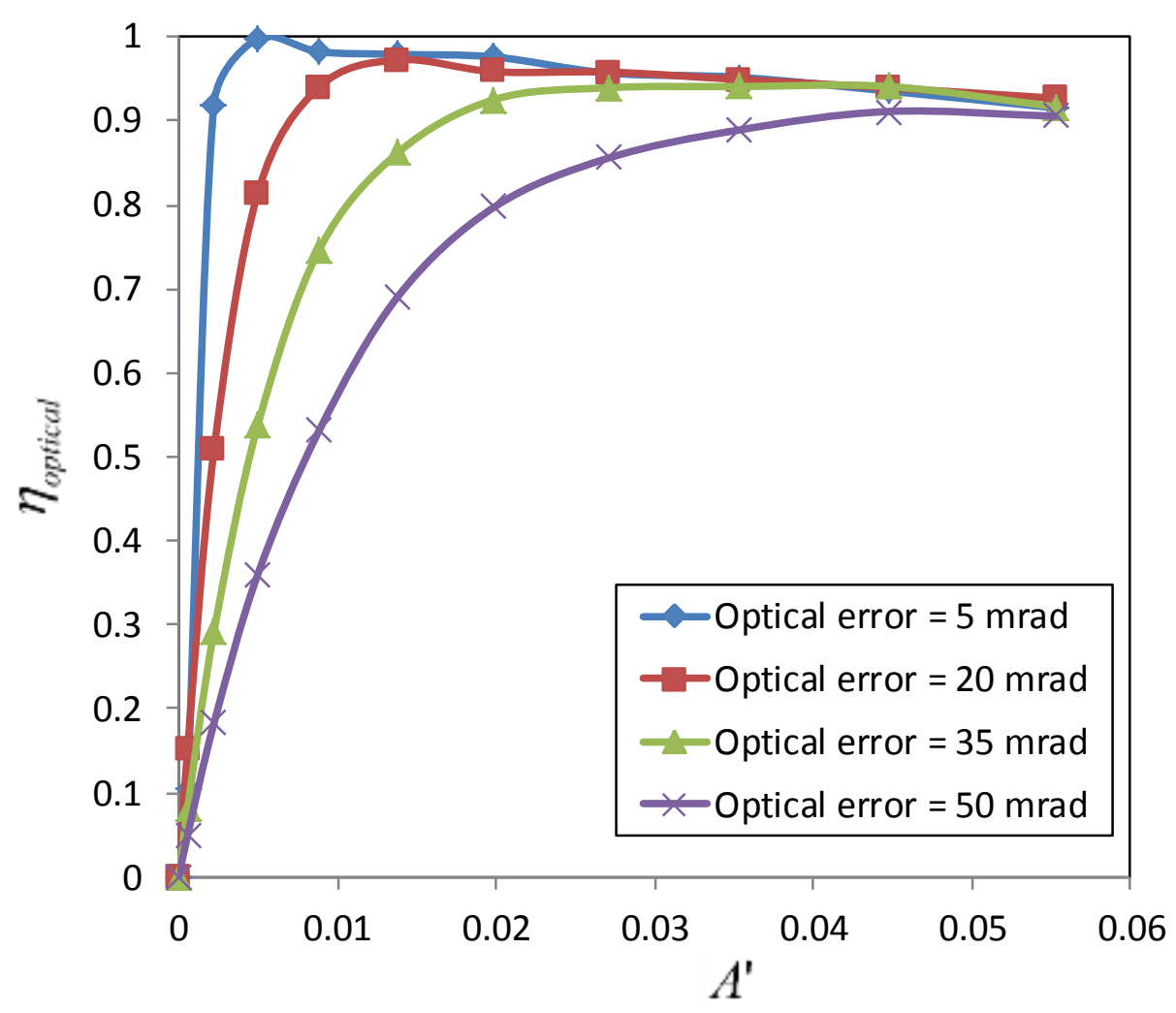

Fig. 7. Optical efficiency for a tracking error of $1^{\circ}$.

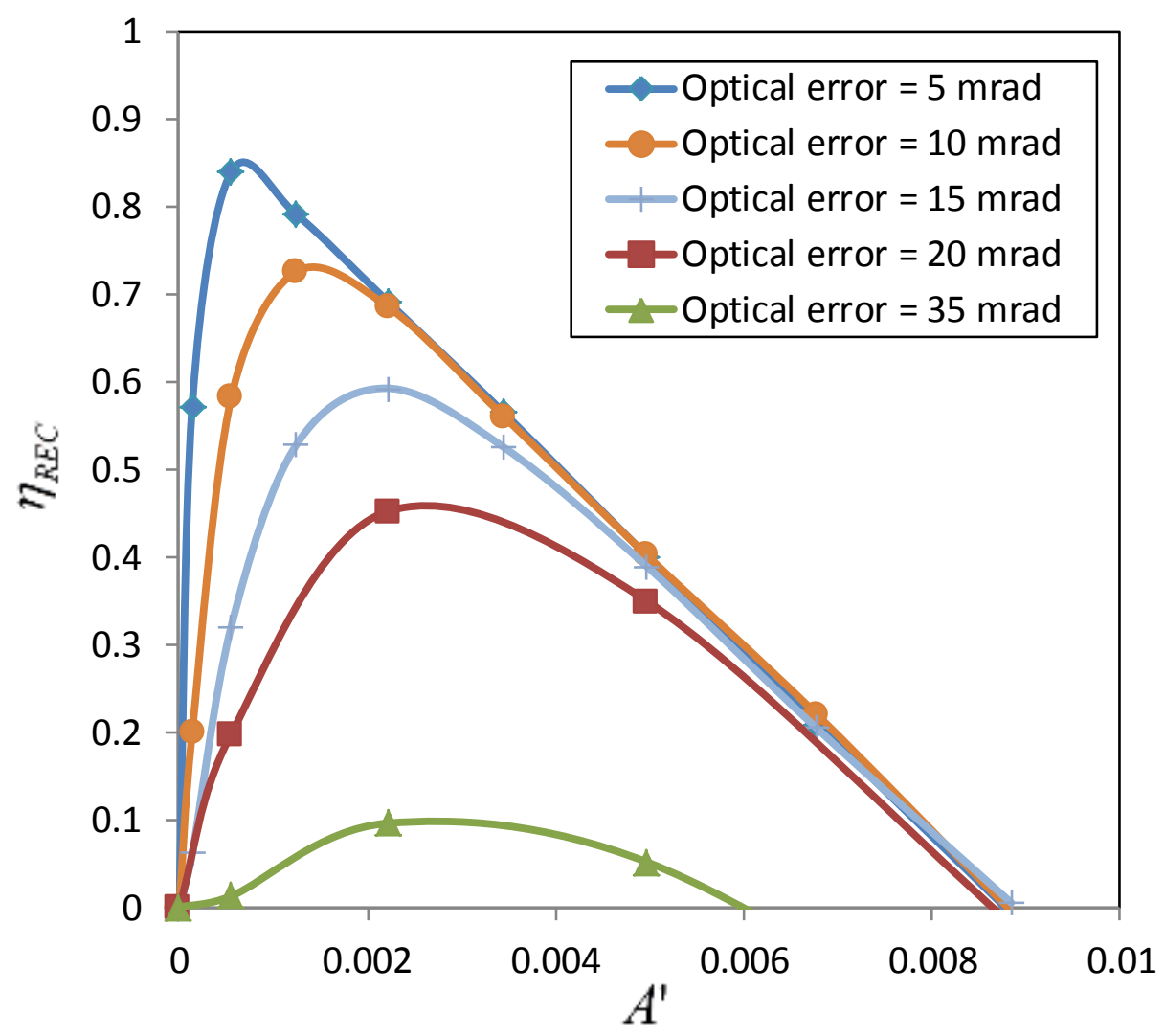

Fig. 8. Overall receiver efficiency for a tracking error of $0^{\circ}$ with receiver surface emissivity of 0.7 . 


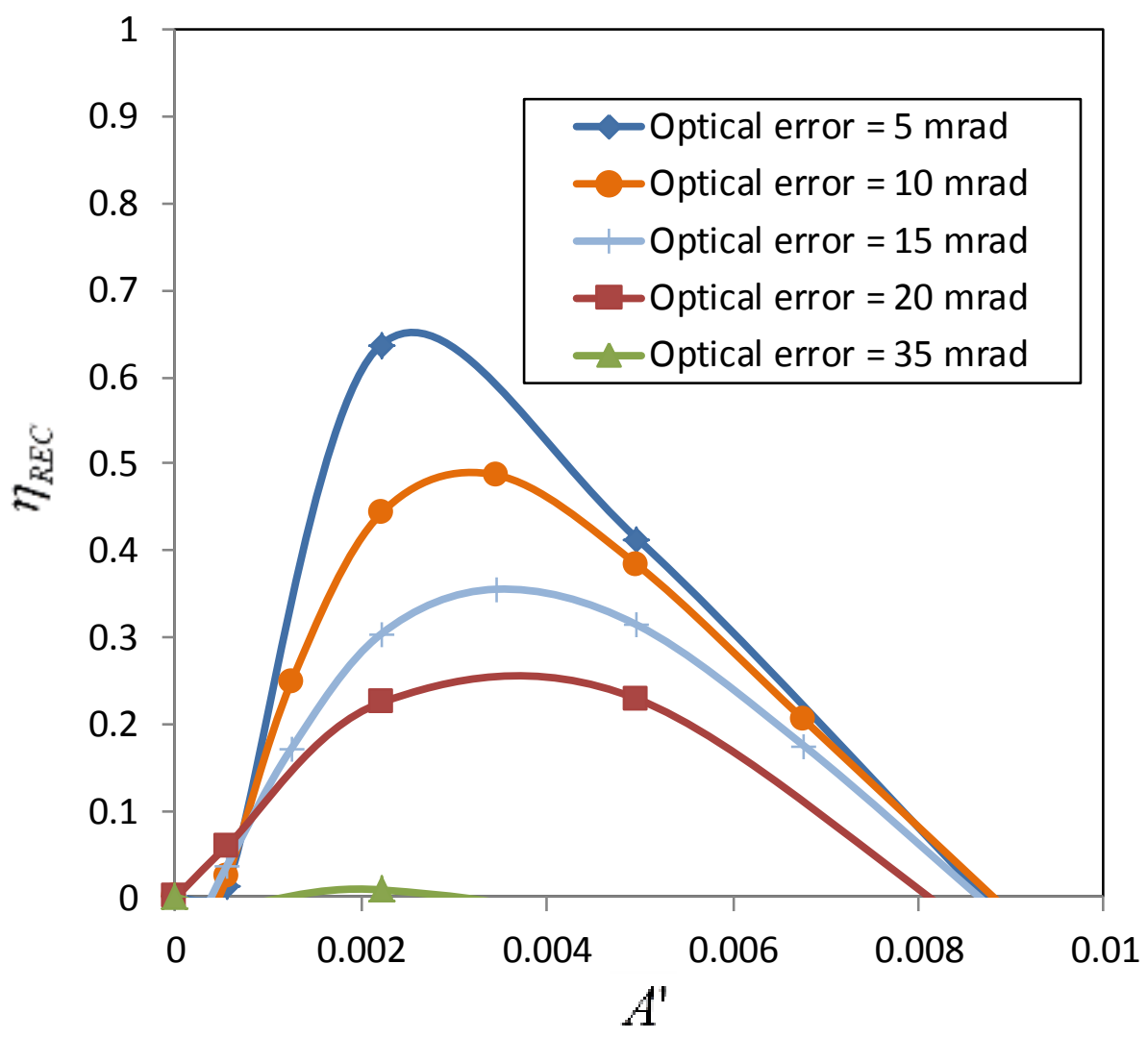

Fig. 9. Overall receiver efficiency for a tracking error of $1^{\circ}$ with receiver surface emissivity of 0.7.

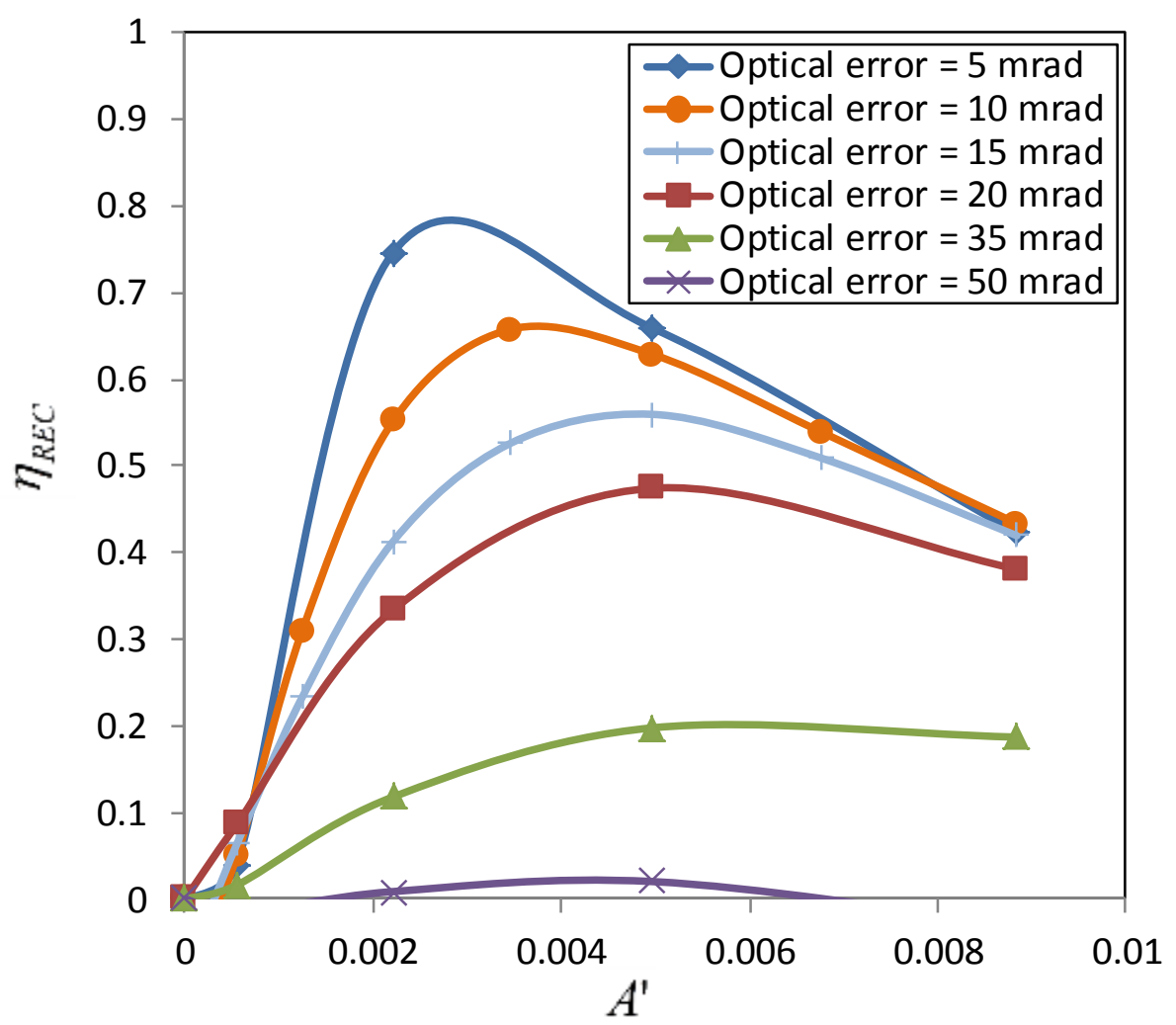

Fig. 10. Overall receiver efficiency for a tracking error of $1^{\circ}$ with receiver surface emissivity of 0.2 . 


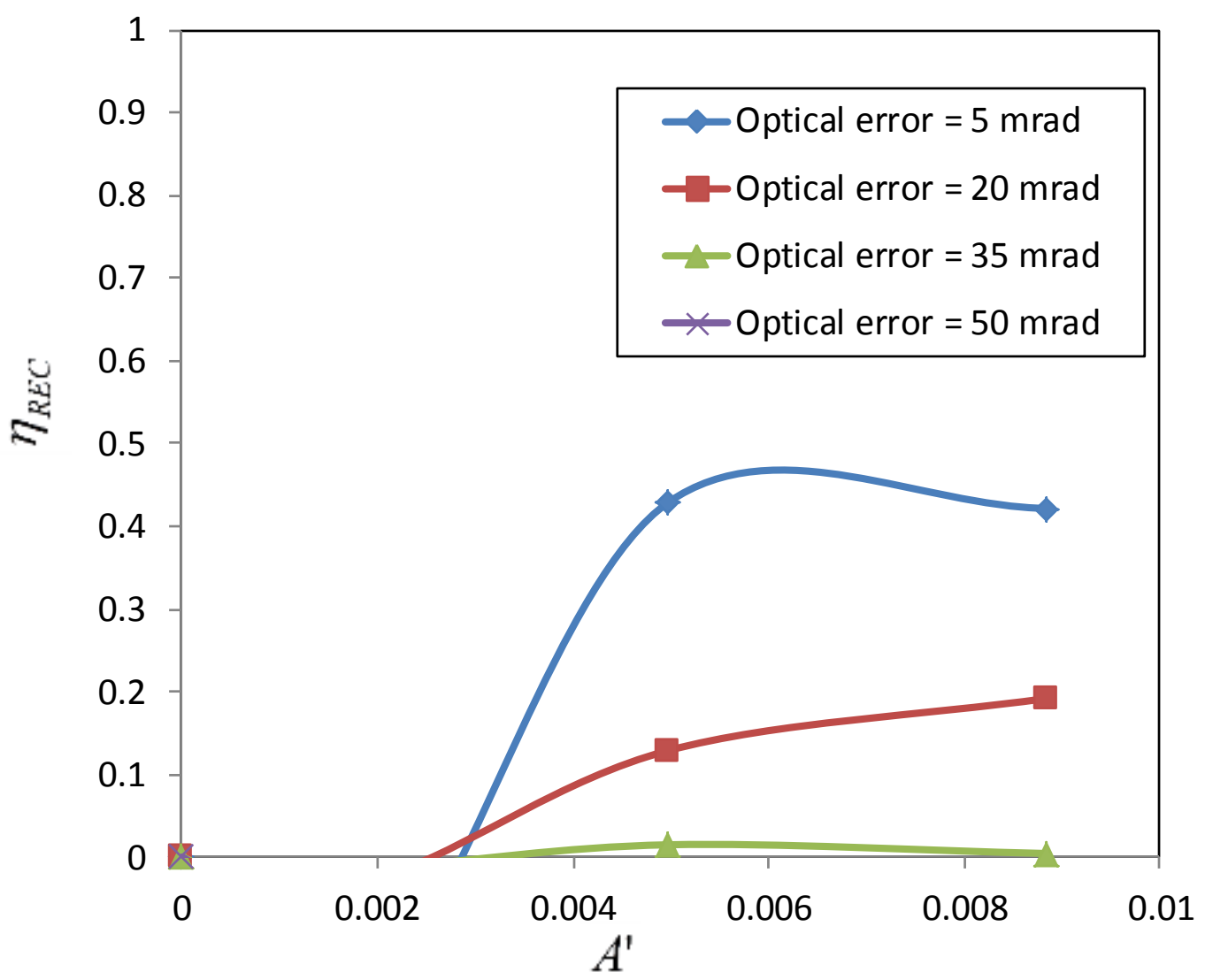

Fig. 11. Overall receiver efficiency for a tracking error of $2^{\circ}$ with a receiver surface emissivity of 0.2 .

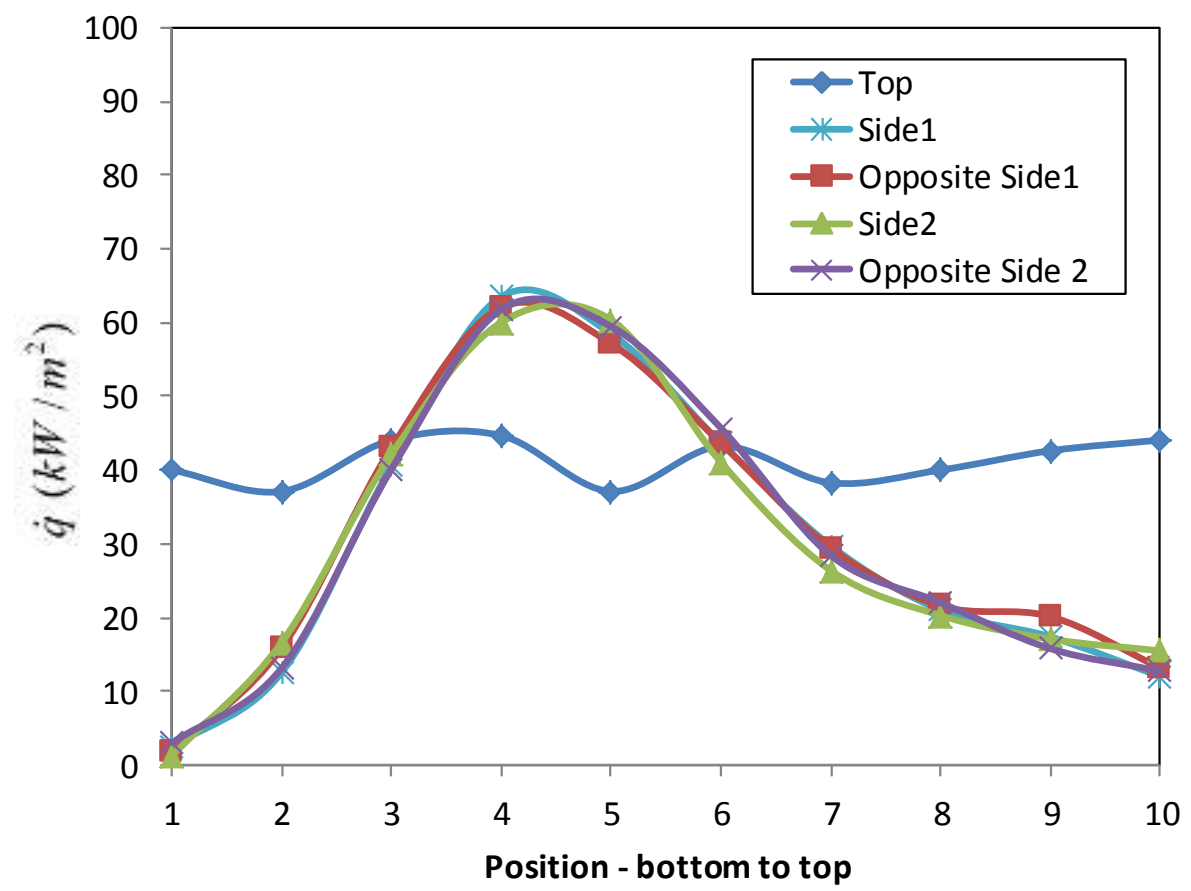

Fig. 12. Heat flux rate at different positions on the different receiver inner walls for a tracking error of $0^{\circ}$. 


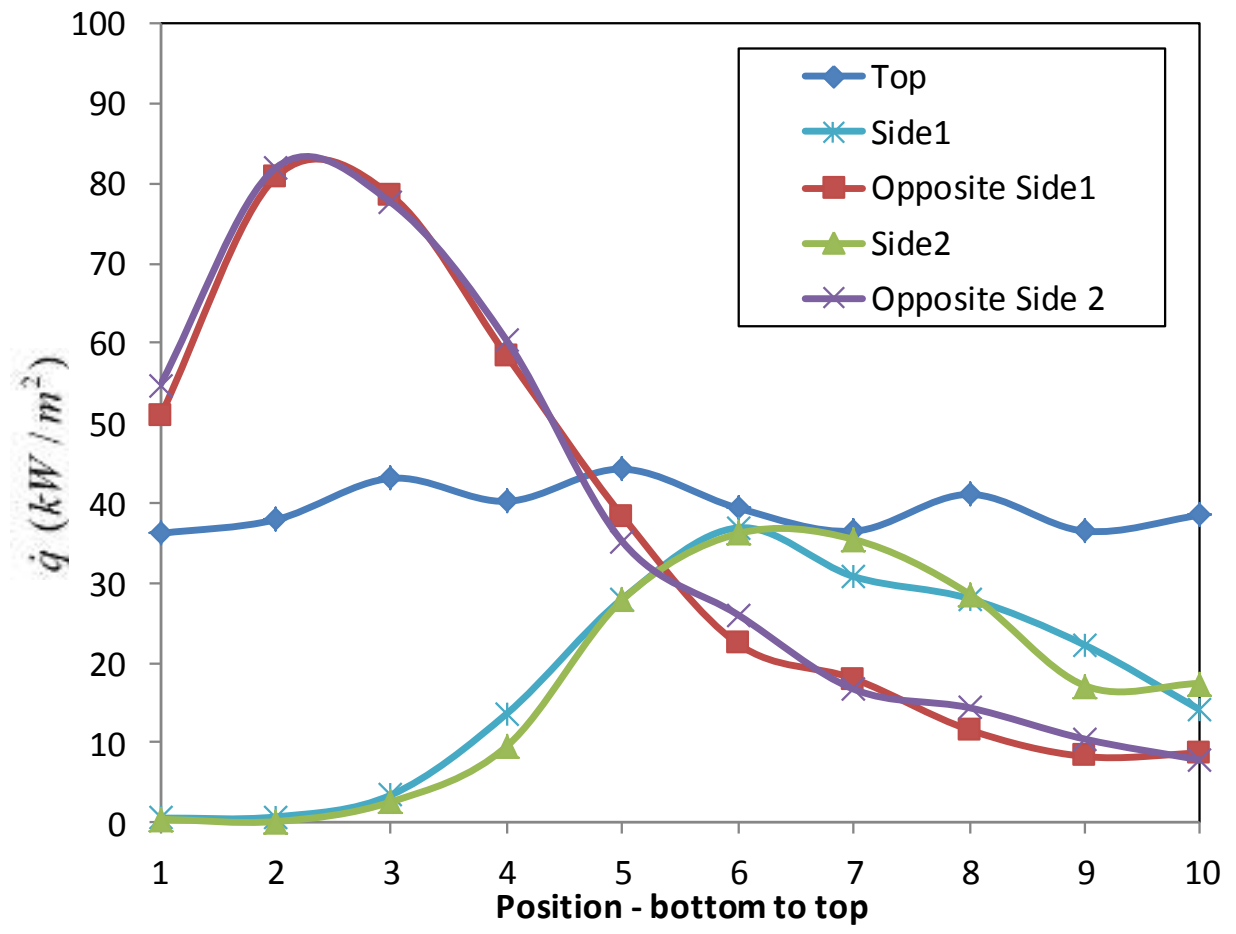

Fig. 13. Heat flux rate at different positions on the different receiver inner walls for a tracking error of $1^{\circ}$.

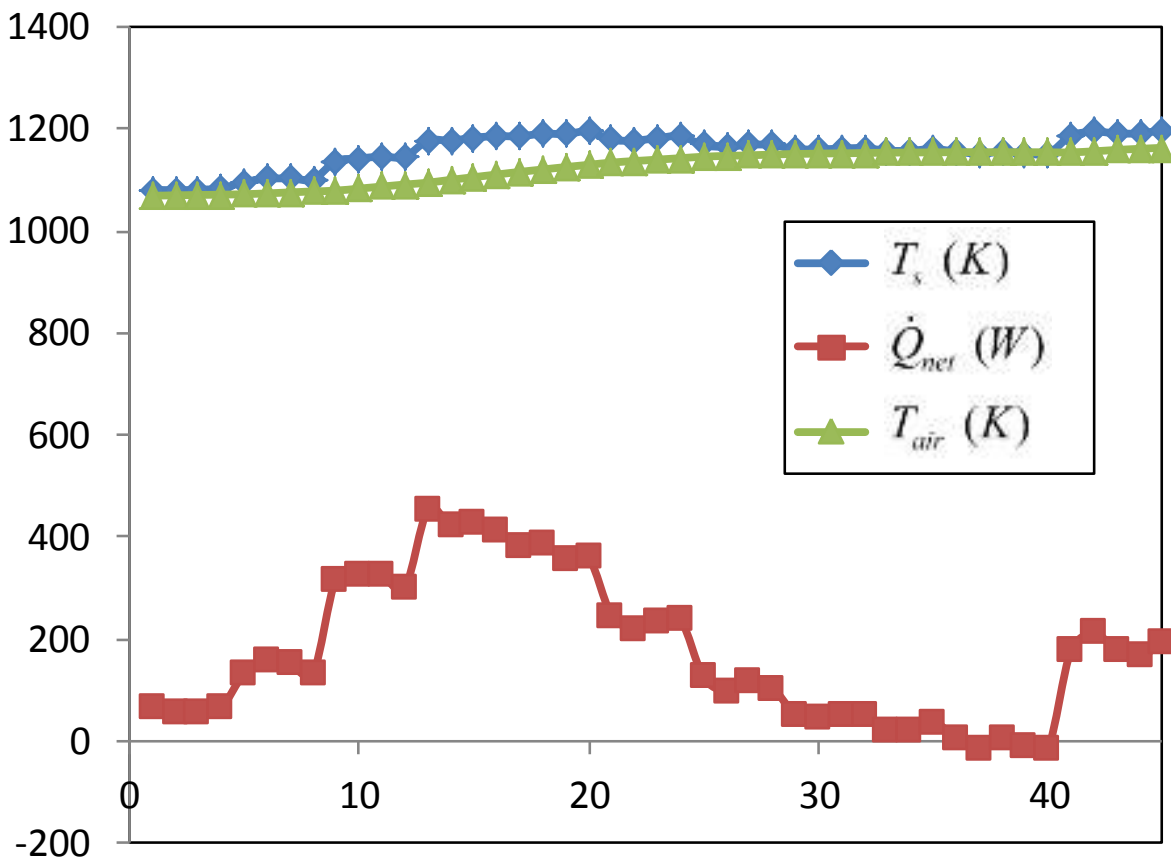

Tube position - bottom to top

Fig. 14. Temperatures and net heat transfer rates for a $50 \mathrm{~mm}$ receiver tube diameter with a tracking error of $0^{\circ}$ and optical error of $10 \mathrm{mrad}$. 


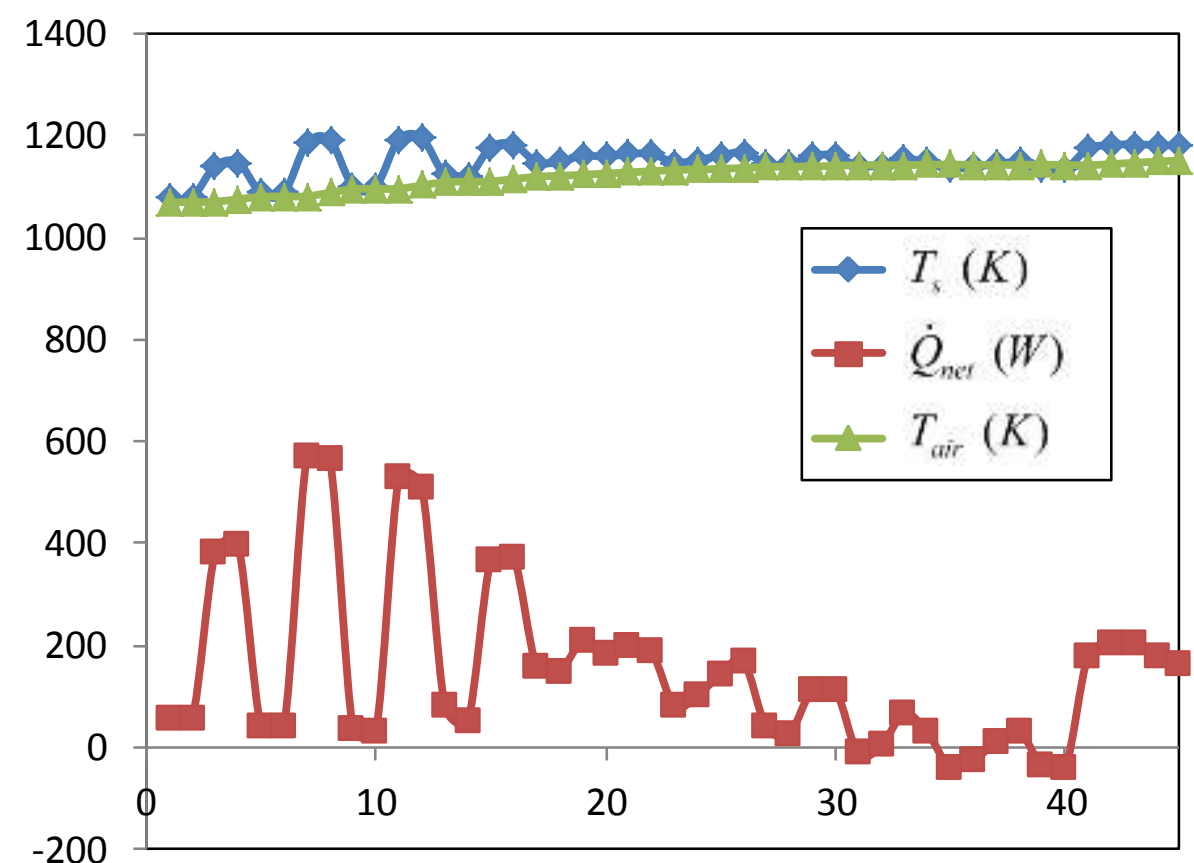

Tube position - bottom to top

Fig. 15. Temperatures and net heat transfer rates for a $50 \mathrm{~mm}$ receiver tube diameter with a tracking error of $1^{\circ}$ and optical error of $10 \mathrm{mrad}$.

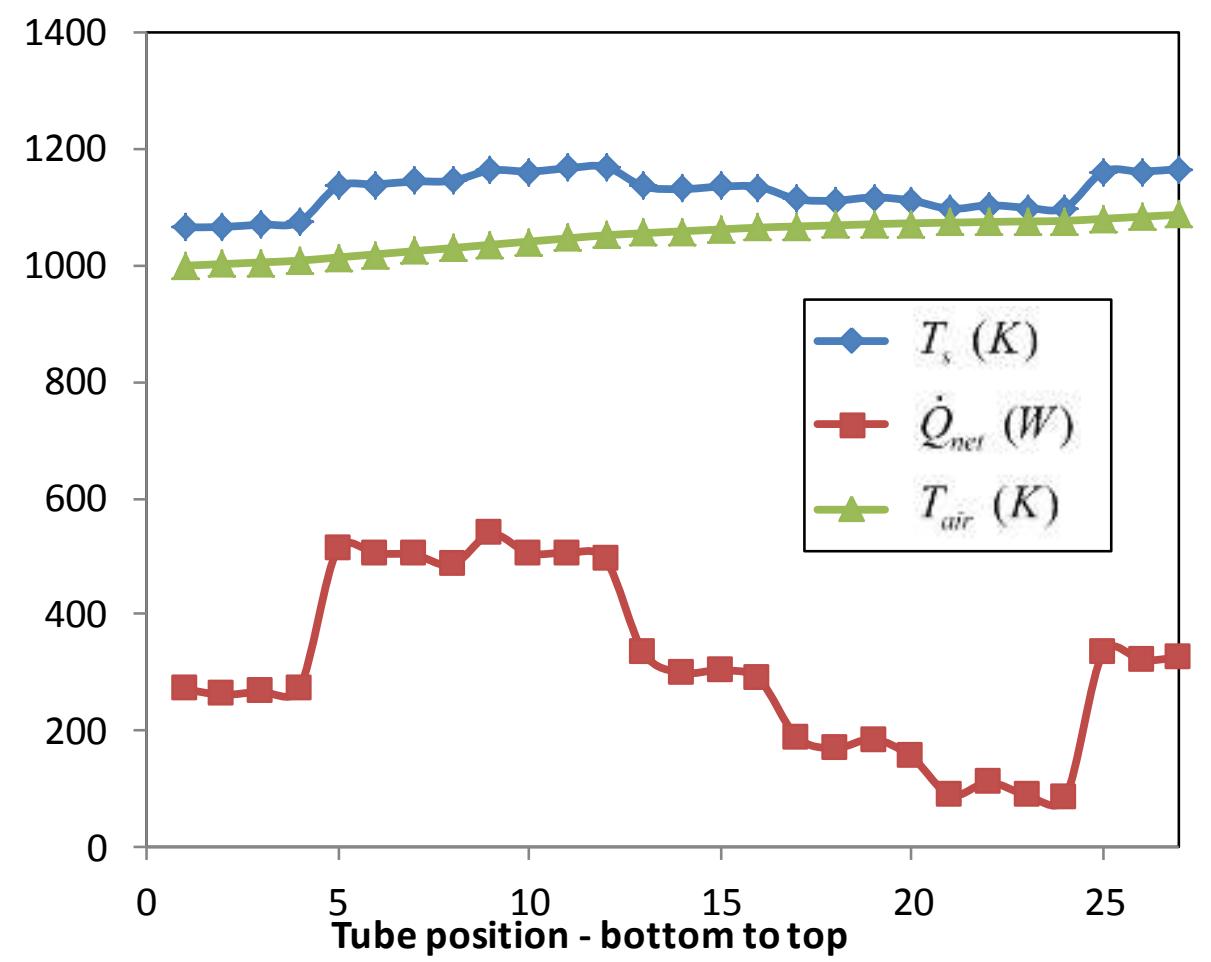

Fig. 16. Temperatures and net heat transfer rates for an $83.3 \mathrm{~mm}$ receiver tube diameter with a tracking error of $0^{\circ}$ and optical error of $10 \mathrm{mrad}$. 


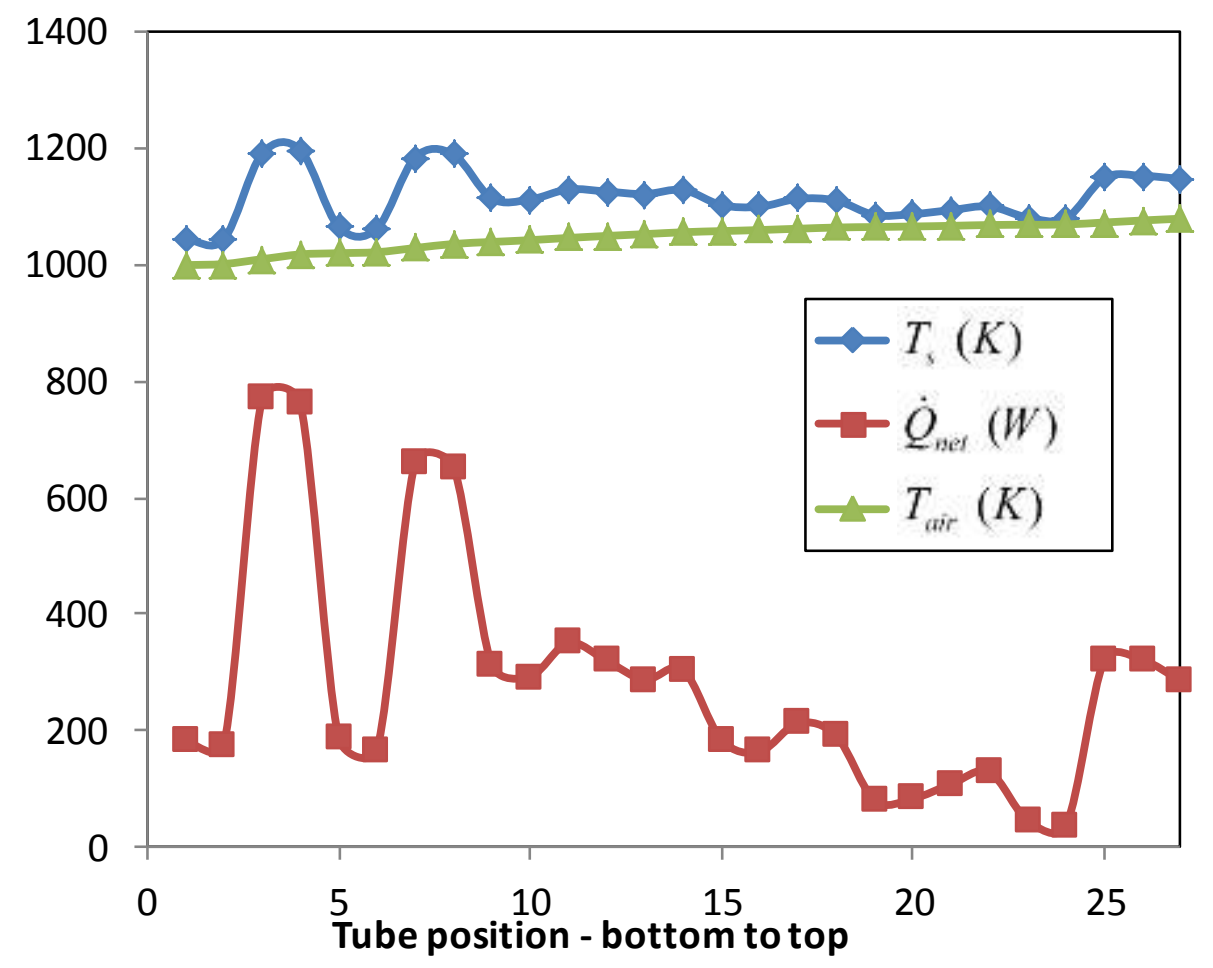

Fig. 17. Temperatures and net heat transfer rates for an $83.3 \mathrm{~mm}$ receiver tube diameter with a tracking error of $1^{\circ}$ and optical error of $10 \mathrm{mrad}$.

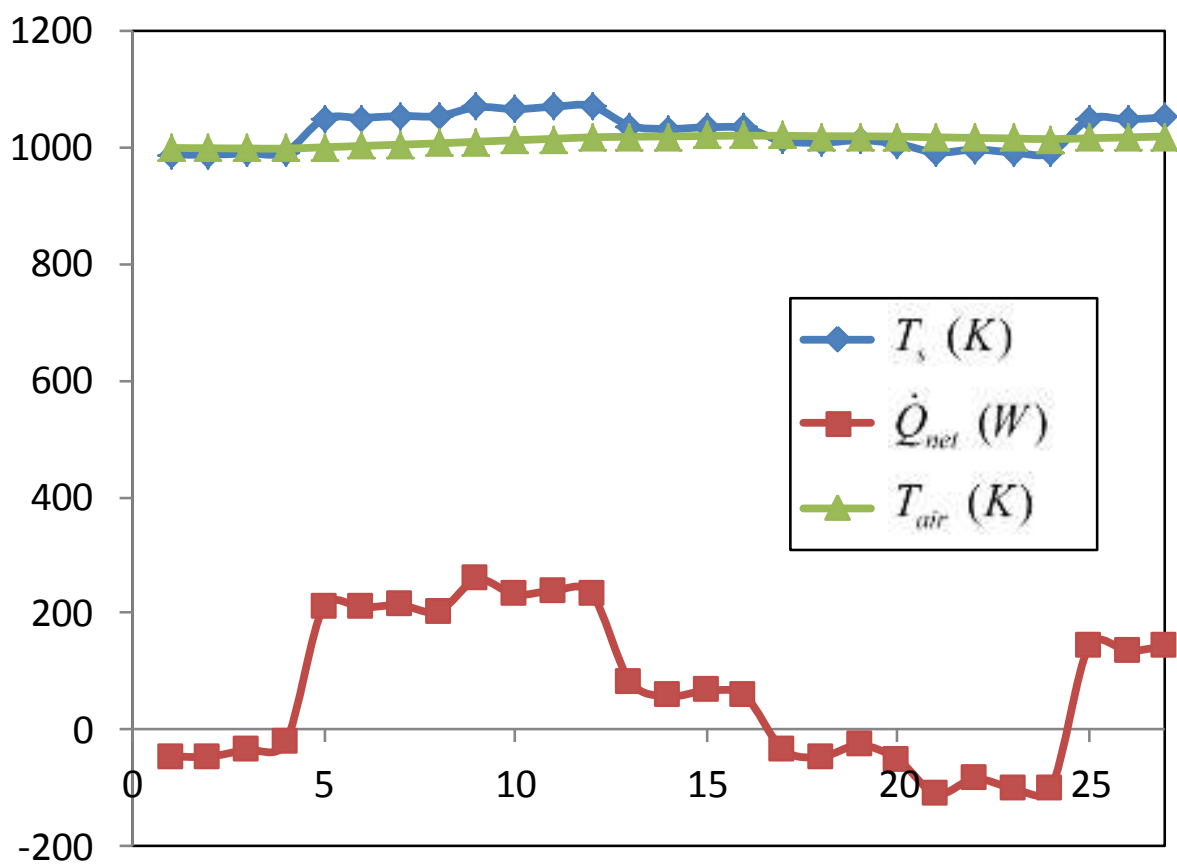

Tube position - bottom to top

Fig. 18. Temperatures and net heat transfer rates for an $83.3 \mathrm{~mm}$ receiver tube diameter with a tracking error of $0^{\circ}$, optical error of $10 \mathrm{mrad}$ and excessively heavy wind. 
Table 1.

Efficiencies of different solar receivers.

\begin{tabular}{|c|c|c|c|c|c|c|c|c|}
\hline Receiver type & $\begin{array}{l}\text { Reference number } \\
\text { or model }\end{array}$ & $\eta_{\text {rec }}$ & $T_{\text {out }}(\mathrm{K})$ & $\begin{array}{l}T_{\text {in }} \\
(\mathrm{K})\end{array}$ & $P(\mathrm{kPa})$ & $\begin{array}{l}\dot{m} \\
(\mathrm{~kg} / \mathrm{s})\end{array}$ & $\begin{array}{l}\text { Working } \\
\text { fluid }\end{array}$ & $\begin{array}{l}\Delta P \\
(\mathrm{~Pa})\end{array}$ \\
\hline \multirow{4}{*}{$\begin{array}{l}\text { Pressurised } \\
\text { volumetric [11] }\end{array}$} & PLVCR-5 & $71 \%$ & 1323 & - & 420 & - & Air & - \\
\hline & PLVCR-500 & $57 \%$ & 1233 & 300 & 415 & - & Air & - \\
\hline & DIAPR [27] & $79 \%$ & 1477 & 308 & 1800 & 0.0222 & Air & 25000 \\
\hline & REFOS [28] & $67 \%$ & 1073 & - & 1500 & - & Air & 1800 \\
\hline \multirow[t]{8}{*}{ Tubular } & {$[16]$} & $51 \% *$ & 1089 & 865 & 370 & 0.73 & $\mathrm{He}-\mathrm{Xe}$ & 7000 \\
\hline & [18] & - & 1023 & 300 & $1600-1900$ & 0.01 & Air & 40000 \\
\hline & [21] & - & 823 & 573 & 650 & - & Air & 10000 \\
\hline & [22] & $82 \%$ & $1500 * *$ & - & 760 & 0.0093 & Air & 40 \\
\hline & [29] & $43 \%$ & 1076 & 876 & 384 & 0.526 & Air & 7330 \\
\hline & [29] & $39.7 \%$ & 1055 & 871 & 375 & 0.516 & Air & 7400 \\
\hline & Solugas [30] & - & 873 & 598 & 850 & 5.6 & Air & \\
\hline & \multicolumn{8}{|c|}{$\begin{array}{l}\text { *calculated by authors } \\
* * \text { proposed }\end{array}$} \\
\hline
\end{tabular}


Table 2.

View factors for tube sections in the different parts of the receiver (for $d=0.05 \mathrm{~m}$ ).

\begin{tabular}{|l|l|l|l|}
\hline $\begin{array}{l}\text { Tube position } \\
\text { (View factor } \\
\text { from) }\end{array}$ & View factor to & $\begin{array}{l}\text { Number } \\
\text { of } \\
\text { transfers }\end{array}$ & View factor \\
\hline Top wall & Aperture & 1 & 0.07 \\
\cline { 2 - 4 } & Other & 40 & 0.0233 \\
\hline Side wall & Top & 5 & 0.0233 \\
\cline { 2 - 4 } & Across & 1 & 0.05 \\
\cline { 2 - 4 } & Left & 1 & 0.085 \\
\cline { 2 - 4 } & Right & 1 & 0.085 \\
\cline { 2 - 4 } & Aperture & 1 & 0.116 \\
\cline { 2 - 4 } & Other & 27 & 0.0211 \\
\hline
\end{tabular}

Table 3.

View factors for tube sections in the different parts of the receiver (for $d=0.0625 \mathrm{~m}$ ).

\begin{tabular}{|l|l|l|l|}
\hline $\begin{array}{l}\text { Tube position } \\
\text { View factor } \\
\text { from) }\end{array}$ & View factor to & $\begin{array}{l}\text { Number } \\
\text { of } \\
\text { transfers }\end{array}$ & View factor \\
\hline Top wall & Aperture & 1 & 0.07 \\
\cline { 2 - 4 } & Other & 32 & 0.0291 \\
\hline Side wall & Top & 4 & 0.0291 \\
\cline { 2 - 4 } & Across & 1 & 0.0625 \\
\cline { 2 - 4 } & Left & 1 & 0.1 \\
\cline { 2 - 4 } & Right & 1 & 0.1 \\
\cline { 2 - 4 } & Aperture & 1 & 0.116 \\
\cline { 2 - 4 } & Other & 21 & 0.0241 \\
\hline
\end{tabular}


Table 4.

View factors for tube sections in the different parts of the receiver (for $d=0.0833 \mathrm{~m}$ ).

\begin{tabular}{|l|l|l|l|}
\hline $\begin{array}{l}\text { Tube position } \\
\text { (View factor } \\
\text { from) }\end{array}$ & View factor to & $\begin{array}{l}\text { Number } \\
\text { of } \\
\text { transfers }\end{array}$ & View factor \\
\hline \multirow{2}{*}{ Top wall } & Aperture & 1 & 0.07 \\
\cline { 2 - 4 } & Other & 24 & 0.0388 \\
\hline Side wall & Top & 3 & 0.0388 \\
\cline { 2 - 4 } & Across & 1 & 0.0833 \\
\cline { 2 - 4 } & Left & 1 & 0.115 \\
\cline { 2 - 4 } & Right & 1 & 0.115 \\
\cline { 2 - 4 } & Aperture & 1 & 0.116 \\
\cline { 2 - 4 } & Other & 15 & 0.0303 \\
\hline
\end{tabular}

Table 5.

Efficiencies of the cavity receiver with $d=0.05 \mathrm{~m}$.

\begin{tabular}{|c|c|c|c|c|c|c|c|c|c|c|}
\hline & & \multicolumn{4}{|c|}{ Tracking error $=0^{\circ}$} & \multicolumn{4}{|c|}{ Tracking error $=1^{\circ}$} & \multirow[b]{2}{*}{$\begin{array}{c}\Delta P \\
(\mathrm{kPa})\end{array}$} \\
\hline $\begin{array}{c}\dot{m} \\
(\mathrm{~kg} / \mathrm{s})\end{array}$ & $\begin{array}{c}T_{i n, 0} \\
(\mathrm{~K})\end{array}$ & $\eta_{\text {rec }}$ & $\eta_{2 \text { ndLaw }}$ & $\begin{array}{c}T_{s, \max } \\
(\mathrm{K})\end{array}$ & $\begin{array}{c}T_{s, \text { ave }} \\
(\mathrm{K})\end{array}$ & $\eta_{\text {rec }}$ & $\eta_{2 n d L a w}$ & $\begin{array}{c}T_{s, \max } \\
(\mathrm{K})\end{array}$ & $\begin{array}{c}T_{s, \text { ave }} \\
(\mathrm{K})\end{array}$ & \\
\hline 0.06 & 900 & 0.66 & 0.67 & 1083 & 1032 & 0.65 & 0.66 & 1069 & 1024 & 56.0 \\
\hline 0.06 & 1000 & 0.57 & 0.70 & 1159 & 1113 & 0.54 & 0.69 & 1153 & 1104 & 56.0 \\
\hline 0.06 & 1070 & 0.50 & 0.72 & 1214 & 1169 & 0.47 & 0.71 & 1211 & 1160 & 56.0 \\
\hline 0.07 & 900 & 0.69 & 0.62 & 1064 & 1016 & 0.66 & 0.61 & 1050 & 1009 & 75.1 \\
\hline 0.07 & 1000 & 0.58 & 0.65 & 1143 & 1099 & 0.56 & 0.64 & 1136 & 1092 & 75.1 \\
\hline 0.07 & 1070 & 0.51 & 0.67 & 1199 & 1157 & 0.48 & 0.66 & 1196 & 1150 & 75.1 \\
\hline 0.08 & 900 & 0.70 & 0.55 & 1049 & 1004 & 0.69 & 0.54 & 1037 & 998 & 97.0 \\
\hline 0.08 & 1000 & 0.60 & 0.58 & 1130 & 1089 & 0.57 & 0.57 & 1124 & 1082 & 97.0 \\
\hline 0.08 & 1070 & 0.52 & 0.60 & 1187 & 1148 & 0.48 & 0.58 & 1185 & 1141 & 97.0 \\
\hline
\end{tabular}


Table 6.

Efficiencies of the cavity receiver with $d=0.0625 \mathrm{~m}$.

\begin{tabular}{|c|c|c|c|c|c|c|c|c|c|c|}
\hline & & \multicolumn{4}{|c|}{ Tracking error $=0^{\circ}$} & \multicolumn{4}{|c|}{ Tracking error $=1^{\circ}$} & \multirow[b]{2}{*}{$\begin{array}{c}\Delta P \\
(\mathrm{kPa})\end{array}$} \\
\hline $\begin{array}{c}\dot{m} \\
(\mathrm{~kg} / \mathrm{s})\end{array}$ & $\begin{array}{c}T_{i n, 0} \\
(\mathrm{~K})\end{array}$ & $\eta_{\text {rec }}$ & $\eta_{2 \text { ndLaw }}$ & $\begin{array}{c}T_{s, \max } \\
(\mathrm{K})\end{array}$ & $\begin{array}{c}T_{s, \text { ave }} \\
(\mathrm{K})\end{array}$ & $\eta_{\text {rec }}$ & $\eta_{2 \text { ndLaw }}$ & $\begin{array}{c}T_{s, \max } \\
(\mathrm{K})\end{array}$ & $\begin{array}{c}T_{s, \text { ave }} \\
(\mathrm{K})\end{array}$ & \\
\hline 0.06 & 900 & 0.64 & 0.73 & 1100 & 1049 & 0.61 & 0.72 & 1098 & 1035 & 17.2 \\
\hline 0.06 & 1000 & 0.55 & 0.75 & 1178 & 1128 & 0.51 & 0.75 & 1179 & 1113 & 17.2 \\
\hline 0.06 & 1070 & 0.48 & 0.77 & 1233 & 1182 & 0.45 & 0.77 & 1236 & 1168 & 17.2 \\
\hline 0.07 & 900 & 0.66 & 0.71 & 1079 & 1033 & 0.62 & 0.70 & 1079 & 1020 & 23.0 \\
\hline 0.07 & 1000 & 0.57 & 0.74 & 1160 & 1113 & 0.52 & 0.73 & 1163 & 1101 & 23.0 \\
\hline 0.07 & 1070 & 0.50 & 0.76 & 1217 & 1170 & 0.46 & 0.75 & 1221 & 1157 & 23.0 \\
\hline 0.08 & 900 & 0.68 & 0.69 & 1063 & 1020 & 0.65 & 0.68 & 1064 & 1008 & 29.6 \\
\hline 0.08 & 1000 & 0.58 & 0.72 & 1146 & 1102 & 0.55 & 0.71 & 1149 & 1091 & 29.6 \\
\hline 0.08 & 1070 & 0.51 & 0.74 & 1204 & 1160 & 0.47 & 0.73 & 1209 & 1149 & 29.6 \\
\hline
\end{tabular}

Table 7.

Efficiencies of the cavity receiver with $d=0.0833 \mathrm{~m}$.

\begin{tabular}{|c|c|c|c|c|c|c|c|c|c|c|}
\hline \multirow[b]{2}{*}{$\begin{array}{c}\dot{m} \\
(\mathrm{~kg} / \mathrm{s})\end{array}$} & \multirow[b]{2}{*}{$\begin{array}{c}T_{i n, 0} \\
(\mathrm{~K})\end{array}$} & \multicolumn{4}{|c|}{ Tracking error $=0^{\circ}$} & \multicolumn{4}{|c|}{ Tracking error $=1^{\circ}$} & \multirow[b]{2}{*}{$\begin{array}{c}\Delta P \\
(\mathrm{kPa})\end{array}$} \\
\hline & & $\eta_{\text {rec }}$ & $\eta_{2 \text { ndLaw }}$ & $\begin{array}{c}T_{s, \max } \\
(\mathrm{K})\end{array}$ & $\begin{array}{c}T_{s, \text { ave }} \\
(\mathrm{K})\end{array}$ & $\eta_{\text {rec }}$ & $\eta_{2 \text { ndLaw }}$ & $\begin{array}{c}T_{s, \max } \\
(\mathrm{K})\end{array}$ & $\begin{array}{c}T_{s, \text { ave }} \\
(\mathrm{K})\end{array}$ & \\
\hline 0.06 & 900 & 0.61 & 0.75 & 1129 & 1080 & 0.60 & 0.75 & 1154 & 1067 & 3.73 \\
\hline 0.06 & 1000 & 0.52 & 0.78 & 1203 & 1153 & 0.50 & 0.78 & 1231 & 1141 & 3.73 \\
\hline 0.06 & 1070 & 0.45 & 0.80 & 1254 & 1205 & 0.43 & 0.80 & 1285 & 1193 & 3.73 \\
\hline 0.07 & 900 & 0.63 & 0.75 & 1108 & 1062 & 0.62 & 0.75 & 1133 & 1051 & 4.99 \\
\hline 0.07 & 1000 & 0.53 & 0.78 & 1185 & 1138 & 0.52 & 0.78 & 1213 & 1127 & 4.99 \\
\hline 0.07 & 1070 & 0.48 & 0.79 & 1238 & 1191 & 0.45 & 0.79 & 1268 & 1181 & 4.99 \\
\hline 0.08 & 900 & 0.64 & 0.75 & 1091 & 1047 & 0.64 & 0.75 & 1037 & 1116 & 6.41 \\
\hline 0.08 & 1000 & 0.55 & 0.78 & 1170 & 1126 & 0.54 & 0.77 & 1197 & 1116 & 6.41 \\
\hline 0.08 & 1070 & 0.48 & 0.79 & 1225 & 1181 & 0.46 & 0.79 & 1254 & 1171 & 6.41 \\
\hline
\end{tabular}

